\title{
Nuevos textos literarios asturianos del XVII y un nuevo testimonio del entremés de L'Alcalde
}

\author{
por Juan C. Busto Cortina \\ Universidá d'Uviéu
}

L

A ReCIENTE publicación de dos ediciones (García Sánchez, 20II; García Sánchez, 20i6), que contienen poesía celebrativa y panegírica, compuesta en el ámbito universitario y colegial de Oviedo durante el siglo XVII, abre nuevas puertas para el conocimiento de la creación poética barroca en Asturias, tanto en castellano y en latín como en asturiano. De uno de estos textos, la Relacion de las fiestas y Certamen poetico celebrados en Oviedo, el año de 1639, con motivo de la declaracion del Patronato de Santa Eulalia de Mérida, era bien conocida su existencia desde que Carlos González de Posada publicase en 1794 el romance del fundador de la literatura en lengua asturiana, Antón de Marirreguera, sobre el Pleitu ente Uviéu y Mérida pola posesión de les cenices de Santa Olaya. Según informara ya Posada, la Relación del certamen fue hecha por el P. Andrés Mendo , rector del Colegio de San Matías. El valor de

' Posada (1794, págs. 71 y 365) fue el primero en hablar de esta copia que Canella confiesa poseer desde 1903 (Canella, I903, pág. 57, n. I). De ella el bibliófilo Antonio García Oliveros hizo un traslado, que pasó luego a la librería personal de don Luis María Fernández Canteli, y que hoy se conserva en la Biblioteca de Asturias «Ramón Pérez de Ayala» de Oviedo, base de la edición mencionada (García Sánchez, 20II). Fermín Canella había hablado de otra copia perteneciente al 
este manuscrito, dado a conocer en su integridad a través de la edición de Justo García Sánchez (20II), permite ahora saber más sobre el que es tenido por primer poema en lengua asturiana y ver el contexto en que surgió. A ello dedicaremos una parte de nuestro trabajo, que trata de completar los datos que se tienen sobre la poesía de Marirreguera y su transmisión manuscrita. Sobre este asunto también habremos de detenernos, pues es bien sabido que, tras la edición liminar de la obra de Marirreguera llevada a cabo por Xulio Viejo (Viejo, 1997), la aparición de nuevos testimonios manuscritos (Busto, 2015) de algunas de sus obras permite no solo un mejor conocimiento de su transmisión textual sino también arrojar luz sobre la evolución del asturiano desde el XVII hacia la lengua actual.

La segunda edición de que hablamos (García Sánchez, 20I6) saca a la luz dos poemas en asturiano dedicados al obispo Ambrosio Ignacio de Spínola y Guzmán (uno en metro de romance y otro en octavas reales), de un autor del todo desconocido hasta la fecha: Juan García de Prada. Con ser su poesía de más bajo vuelo que la del arcipreste de Carreño, tiene esta un gran valor como testimonio de la continuidad en el empleo literario del asturiano a lo largo del XVII para este tipo de poesía celebrativa compuesta al calor de acontecimientos relevantes.

\section{NuEVOS POETAS EN ASTURIANO Y CASTELLANO EN CERTÁMENES BARROCOS}

Es evidente que, a partir de estas dos publicaciones, el panorama de la poesía barroca en Asturias queda considerablemente ampliado. Además, el descubrimiento de un nuevo poeta en lengua asturiana, el mencionado Juan García de Prada, unido al conocimiento de su poesía, confirma

canónigo Lope Valdés, y creía probable que fuese el mismo manuscrito del que se sirvió Posada, que de Jovellanos habría pasado a Caveda (Caveda-Canella, i887, pág. 57, nota). 
lo que hace más de un siglo adelantó Fermín Canella: que «algunos hijos del país y de su Universidad escribieron en bable a la manera de González Reguera». Canella, que poseía copia manuscrita del Certamen... de Santa Eulalia de Mérida, sin duda, recordaba lo dicho tiempo atrás por su primer compilador, el P. Andrés Mendo, al final del certamen quinto: «otros romances en lengua asturiana salieron de mucha gracia: mas, por que no la tendrán para quien no sabe el lenguaje, se dejan [de copiar]» (García Sánchez, 20II, pág. 59).

Cabe preguntarse si alguno de los que intervinieron en I639 en la celebración a Santa Eulalia fue también autor de otro de los romances en bable presentados en el quinto certamen, que no fueron premiados ni transcritos, pues a menudo los mismos poetas solían acudir con más de una composición. Canella ya había adelantado el nombre de alguno de los participantes en uno de los ocho certámenes: el del cura de Bobes, D. Juan de Noriega, y los de los hermanos Tomás y Faustino Serrano de Paz. Los tres tuvieron una intervención destacada. Juan de Noriega, del que solo se sabe que era cura de Bobes, compuso una loa que fue representada el jueves 22 de septiembre dentro de la Catedral y no en la plaza, pues era día lluvioso, y además obtuvo un segundo premio por un soneto que presentó al octavo certamen. De Tomás (I623-Oviedo, I693) y de Faustino (¿?-Oviedo, 1674) Serrano de Paz ya tratamos hace años (Busto, 200o; Busto, 2002) al examinar a los autores que intervinieron en los certámenes celebrados en Oviedo en I665 y I666². Sin embargo, las recientes investigaciones sobre esta familia de origen

${ }^{2}$ Ambos fueron publicados al año siguiente: Relacion de las exequias que en la muerte del Rey nuestro señor don Felipe quarto el Grande, Rey de las Españas, y Emperador de las Indias hizo la Vniversidad de Oviedo en el Principado de Asturias / ofrecela... la misma vniversidad, Madrid, por Pablo del Val, I666, 294 págs. en 4. ${ }^{\circ}$; y Certamen poético a la gloriosa Virgen y Martyr Santa Eulalia de Merida, Patrona del Obispado y Ciudad de Oviedo... Dedicado a Don Ambrosio Ignacio de Espinola y Guzman, Ovispo de Oviedo y Arzobispo electo de Valencia, por Don Phelipe Bernardo de Qviros y Benauides, Valladolidad, por Ines de Loxedo, I667, 25 I págs., en 4.. 
portugués asentada en Oviedo en I63I a partir del nombramiento del padre, Leonel Serrano de Paz, como médico por el cabildo ovetense, han acrecentado la información de que se disponía sobre los mencionados y sobre alguno de los otros hijos mayores: Manuel (Braganza, I605-Oviedo, I673); Juan (Orense, I608-Esmirna, I672) y Francisco (Monforte de Lemos, I6I5-??). Faustino Serrano de Paz regentó diversas cátedras en la Universidad (García Sánchez, 20I2, págs. 47-54) y concursó en el Certamen de i639 en el que obtuvo un segundo premio por unas octavas, siéndole también transcritas (aunque no habían sido premiadas) unas glosas a una redondilla dentro del tercer certamen. En las Exequias de Felipe IV actuó como juez y por ello fueron impresas sus poesías (una canción real, dos epitafios latinos y dos series de endechas), aunque no concurrió, y también en el Certamen de Santa Olaya de i666, donde obtuvo un primer premio por dos series de coplas de arte mayor (a los otros asuntos presentó un soneto, una glosa en cuatro décimas y doce quintillas) [Fuertes Acevedo, I867, t. II, s. n.; Suárez, I959, t. VII, págs. II6-II7; Busto, 2002, pág. I07]. Por lo que se refiere a Tomás, de todos los hermanos la figura mejor conocida (García Sánchez, 20I2), fue abogado y catedrático de la Universidad de Oviedo. En la celebración de I639 parcitipó con unas glosas a una redondilla por las que obtuvo el segundo premio en el tercer certamen, y en el sexto certamen, aunque no obtuvo premio, fue transcrito un jeroglífico suyo. Como se ha venido señalando (Posada, 1989, pág. I20; Fuertes Acevedo, I885, págs. I92-193; Suárez, I959, t. VII, págs. II8-II9; Busto, 2002, págs. I08-I09), además participó en las honras fúnebres de 1665 donde pronunció la Oratio funebris, un epicedio también en latín que fue premiado en el primer certamen (aunque renunció al mismo), y un epitafio en griego y en latín, con el que obtuvo el primer premio. Tambien concurrió al Certamen en honor de Santa Eulalia de Mérida de I666 con una glosa en tres décimas con las que obtuvo el tercer premio en el asunto segundo. 
Además de los reseñados, del resto de poetas que intervinieron en el certamen de I639 solo Estevan González de Candamo volverá a aparecer en alguna de las otras dos celebraciones de la segunda mitad de siglo. Siendo aún estudiante conseguiría en I639 el primer premio en el primer certamen por un poema en latín, y también en la referida relación será transcrito un jeroglífico suyo que se presentó al sexto certamen aunque no fue premiado. Y con el título de doctor y catedrático de cánones, se mencionará a González de Candamo en el certamen de Felipe IV, así como en el de Santa Eulalia de Mérida de 1666 donde participa con dos sonetos, uno de ellos heroico, que fueron impresos.

Entre el resto de los que intervinieron en el certamen de I639 destacan los hermanos jesuitas vinculados al propio Colegio de San Matías y su director, el mencionado P. Andrés Mendo, quien obtuvo el primer premio en el certamen séptimo por cuatro décimas. En la Relación que este hizo del certamen introdujo unas octavas reales suyas (en el cuarto) y unas glosas (en el tercer certamen), aunque no habían sido premiadas. También fueron transcritas varias poesías del hermano Xavier de la Fresneda que no obtuvieron galardón: un poema latino (en el primer certamen), unas glosas (en el tercero) y un soneto (en octavo). De Miguel de Avendaño, entonces hermano y estudiante, no se copió el poema latino por el que había conseguido un segundo premio en el primer certamen, pero sí un romance en el certamen quinto (que no fue premiado) en el cual se hacía un curioso remedo del euskera, del gallego y del portugués. Otros hermanos jesuitas resultaron también premiados, como Juan Osorio (segundo premio en el primer certamen), cuyo poema no fue transcrito, Pedro de Paladinas (tercer premio en el tercer certamen), Tomás de Donvidas (segundo premio en el quinto certamen), Antonio de Hermosilla (segundo premio en el sexto certamen) o Gabriel Bernardo de Quirós (autor del laberinto). 
Otros religiosos que concurrieron al certamen fueron los benedictinos Fray Bernardo de la Puerta, lector de Teología, de quien se transcriben seis estancias dentro del segundo certamen, que había quedado desierto, y un soneto con el que obtuvo el primer premio en el octavo; y Fray Joseph Cardoso, ganador del primer premio en el tercer certamen por una glosas a una redondilla, y de un tercero por un jeroglífico presentado al sexto certamen. A ellos se suma un único representante de la orden de Santo Domingo, el maestro Fray de Llano que fue el primer premiado en el certamen sexto por un jeroglífico. Del ámbito universitario procedía Nicolás del Cantillo, catedrático de Vísperas de Leyes, cuyas octavas reales lograron el primer premio en el cuarto certamen y que también vio recogidas cuatro décimas suyas, presentadas al certamen séptimo, que no fueron premiadas, y también Juan de Granda, maestro de Teología, que recibió el segundo premio por cuatro décimas presentadas al séptimo certamen. Entre los cercanos al obispo Valdés Herrera se hallaba su secretario Francisco Gutiérrez Pérez, quien con su primer premio adelantó a Marirreguera, y del que también se transcribe un soneto que sin embargo no había sido presentado al octavo certamen. Y también del paje del obispo, Mateo Sánchez, se trascribieron unas glosas que no habían sido premiadas. Asimismo intervino Agustín de Espinosa, racionero de la catedral, que obtuvo el tercer premio por un soneto presentado al octavo certamen. Por último, al clero rural secular pertenecía, con Marirreguera, el cura de Regla, Antonio de Miranda, que consiguió un tercer premio en su cuarto certamen. Ninguna información se dispone sobre otros concurrentes como Bernardo de Vigil, que no fue premiado pero del que se transcriben cuatro octavas reales, o Toribio Montes, que obtuvo el tercer premio en el certamen séptimo pero cuyas décimas no habían sido premiadas.

El colector omitió los nombres de los autores de un «romance en metro", atribuido a "cierto cura», y del romance que compuso «cierto poeta» donde se hacía resumen de las celebraciones en honor a Santa 
Olaya, redactado en sayagués a imitación del Romance sayagués burlesco de Quevedo, pero con un empleo mucho más intenso y puro de esta lengua.

Así pues, a través de la relación hecha por el P. Andrés Mendo del Certamen... de Santa Eulalia de Mérida es posible conocer mejor la actividad poética que acompaña al surgimiento del primer texto literario en asturiano. Este de I639, a diferencia de los certámenes celebrados casi tres décadas más tarde, era hasta hace pocos años prácticamente desconocido. Llama la atención que en el tiempo que media entre uno y otro momento dejen de aparecer buena parte de los poetas que habían intervenido en I639. En este sendido cabe recordar que los últimos estudios biográficos sobre Marirreguera ${ }^{3}$ insisten en separarlo del Antonio Álvarez que participó en las Exequias de Felipe IV de 1665 con una elegía en latín (segundo asunto), por la que obtuvo un tercer premio, al cuarto con un soneto y al sexto asunto con una glosa en cuatro décimas (que no se leyó pero sí fue impresa). Contra la opinión de González de Posada y de Constantino Suárez, que identifican al autor de estos poemas con Marirreguera, Xulio Viejo piensa que se trata de dos poetas distintos, este último (Antonio Álvarez) sería posterior a Marirreguera, pues habría nacido hacia 1632.

En definitiva, de los veintitrés poetas (ocho de ellos vinculados a la Compañía de Jesús) que intervinieron en el certamen de I639, tan solo tres reaparecerán en posteriores certámenes: Estevan González de Candamo y los hermanos Tomás y Faustino Serrano de Paz. La participación

3 Xulio Viejo (Viejo, 1997, págs. 15-22 ) cree que Antonio González Reguera pudiera responder al apellido de la madre, siendo Álvarez o Álvari el del padre. Cabe recordar que la tradición erudita ha fijado el patronímico González Reguera, mientras que los manuscritos (todos del XvIII o principios del xix) transmiten el de Antonio Álvarez. En este sentido el ms. copiado por García Oliveros (a partir de uno del xviI) donde figura Antonio de Reguera, cura de Prendes no aporta ninguna luz sobre este asunto ni tampoco el manuscrito de El alcalde que aquí presentamos, donde aparece como «Anton de Maria Reguera». 
de estos dos hermanos en ambos certámenes (Faustino, además, como juez en las Exequias de Felipe IV), los sitúa como figuras preeminentes en el mundo cultural asturiano de mediados del xvis, aunque por debajo de su otro hermano, $\mathrm{Manuel}^{4}$, encargado de publicar la convocatoria del certamen de I665. Otros literatos que intervinieron en los dos certámenes de 1665 y 1666 fueron Felipe (o Felipe Antonio) Bernardo de Quirós y Benavides, Antonio Llanes Campomanes o Francisco de la Pola Argüelles, junto a otros nombres práctimente desconocidos como Francisco Argüelles Lorenzana, Fray Pedro de Bárcena, Dionisio Bernardo de Quirós, Juan de Contreras, Álvaro Dasmarinas Pumarino, Pedro Fernández Palacio (o Palacios) Argüelles, Juan Ordóñez Campomanes, José de Solís Valdés o José Villamayor y Vivero. La nómina de poetas queda considerablemente ampliada con aquellos poetas que intervinieron en un solo certamen. Además de los mencionados, los poetas que tomaron parte solo en las Exequias de Felipe IV en I665 fueron veinticuatro, y treinta y dos fueron los que participaron en el certamen de Santa Eulalia de Mérida de 1666 (Busto, 2002, págs. IOI-II8). Entre los autores más importantes cabe mencionar a Francisco Antonio Bernardo de Quirós y a Diego de Sierra Valcarce, entre los participantes en el certamen de I665 (Busto, 2000, págs. I26-I27), y a Andrés Llanes Estrada, rector de la Universidad, que intervino en el de $\mathbf{} 666$.

Siguiendo a lo apuntado por Canella, hemos defendido (Busto, 2002, pág. 92) que al lado de Marirreguera, autor de una obra relativamente abundante, tuvo que haber otros poetas que compusiesen en asturiano

${ }^{4}$ Como comentador de Góngora y copista de manuscritos medievales, su figura ha sido objeto de diversos estudios. A los trabajos biográficos de ámbito asturiano (Posada, I989, pág. IO2; Suárez, I959, t. VII, págs. II7-II8; Busto, 2002, págs. I07-IO8, donde se reproduce la información ofrecida por Fuertes Acevedo, I867, t. II, s. n.), se añaden otros que tratan sobre sus comentarios a las Soledades (Alonso, 1982, págs. 496-508; Roses-Jammes, 1994, págs. 58-60; García Sánchez, 20I2, págs. 7-IO; Ponce Cárdenas, 20I4) o el muy novedoso donde se le atribuye la autoría de la copia del Livro da montaria de Joâo I (Conde, 20IO, págs. 97-II4). 
de forma ocasional y que no alcazaron el prestigio del de Carreño, cuya memoria y cuya obra, aun sin ser impresa, fue capaz de perdurar más de un siglo. Ello se confirma ahora con la referida edición de los dos poemas en asturiano del hermano Juan García de Prada (I60o-I673/4), dedicados al obispo Ambrosio Ignacio de Spínola y Guzmán'. Estos poemas forman parte del homenaje literario que los colegiales jesuitas de San Matías rindieron al mencionado obispo en 1667, durante el corto periodo que este regentó la sede de Oviedo ${ }^{6}$. Tanto el texto en prosa como los poemas que siguen en el manuscrito recientemente exhumado (fols. 279 r -30I v) ${ }^{8}$ son obra de Matías de los Reyes Valenzuela, con excepción de los mencionados en asturiano de Juan García de Prada y de una composición anónima que comienza «La questión, que e de excitar». Justo García Sánchez (2016, pág. 52) destaca la importancia del celebrado obispo señalando que «difícilmente podemos entender la abundante creación literaria, que se manifiesta bajo su episcopado ovetense, si no tenemos en cuenta su personalidad y la de sus más directos colaboradores». Ignacio de Spínola llegaba al Principado apenas para ver su nombre impreso en la licencia de las Exequias de Felipe IV que firma un familiar del obispo, Juan Baptista del Vado, el 9 de enero de 1666.

5 Ambrosio Ignacio de Spínola y Guzmán (Madrid, I632-Sevilla, I684) era hijo del primer marqués de Leganés y primo del Conde-Duque de Olivares, bajo cuya tutela fue educado. Tras ocupar diversos obispados fue nombrado arzobispo de Sevilla el 29 de noviembre de 1669 (García Sánchez, 20I6, págs. I8-88).

${ }^{6}$ Llegó a Oviedo el I4 de diciembre de 1665 para regir la diócesis hasta finales de agosto de I668 (García Sánchez, 20I6, pág. 35). Los jesuitas lo debieron de ver como proclive a sus intereses, pues había aprendido sus primeras letras con la Compañía y venía acompañado por Matías de los Reyes Valenzuela, que había estudiado en el Colegio de la Compañía de Jesús de Córdoba y por el jesuita extremeño P. Gabriel de Aranda (García Sánchez, 20I6, págs. 89-98 y 5I-52).

7 Lleva por título: Relación de la recluta poética hecha por la Magestad Délphica en el Principado de Asturias. Año de 1667 (n. ${ }^{\circ}$ I, págs. III-I4I).

${ }^{8}$ Se trata del ms. 57-3-32 de la Biblioteca Colombina de Sevilla, de cuyo hallazgo y edición da cuenta Justo García Sánchez (2016, págs. I3-18). En el catálogo figura como Opuscula varia [Manuscrito], s. XVII, [345] h.; 2IO x I55 mm. Ms. copiado por varias manos. 
Sin embargo, cabe recordar que ningún jesuita había intervenido en este certamen celebrado hacía solo dos meses. Por su parte, el certamen a Santa Eulalia que tuvo lugar en I666, dedicado a Ignacio de Spínola que actuó también como juez, dio entrada a tres composiciones (seis octavas, cuatro décimas y una canción) de poetas de la Compañía, cuyo nombre extrañamente se calla (págs. 50, 99, II6 y I3I), que obtuvieron terceros premios (en los asuntos tercero, cuarto y quinto), y a un soneto que no fue premiado pero sí editado. El plazo para la presentación de originales terminaba el trece de septiembre, y a esta circunstancia parece referirse uno de los poemas de Matías de los Reyes, el titulado Respuesta a un Romance Panegírico que me embió la Academia de Oviedo. Ottubre de I666, que comienza "Gloriosos hijos de Apolo / que pisáis lo más excelso", cuando dice:

Yo el Idiota del Parnaso
(que este grado me dio Phebo
por dos mal escritas coplas
y un bien borrado soneto).

El otro poema de Matías de los Reyes tuvo que ser compuesto poco después del I4 de mayo de I677, pues va dedicado $A$ la promoción del Illustrisimo señor D. Ambrosio Ignacio Spinola y Guzmán... al Arzobispado de Santiago (n. ${ }^{\circ}$ 6, págs. I6I-I64) y consta de once octavas reales («Si me infundiste tu furor divino»). Los otros dos poemas en castellano son anónimos y tienen por destinatario al propio Matías de los Reyes, el que comienza "La questión que e de excitar» (n. ${ }^{3}$ 3, págs. I46-I50) y la serie de catorce octavas reales que comienzan «En carroza de luz resplandeciente» (n. ${ }^{\circ}$, págs. I64-I67).

Los poemas en asturiano son los dos mencionados de Juan García de Prada. El primero (n. ${ }^{\circ}$ 3, págs. I5O-I54) lleva por título: «Romance en idioma asturiano a la entrada del Illustrísimo señor D. Ambrosio Ignacio de Espínola y Guzmán» (n. ${ }^{\circ}$ 4, págs. 150-156) y es un romance octosi- 
lábico de Io8 versos en cuartetas asonantadas. Debió de ser compuesto poco después de la llegada del obispo a Oviedo, a cuyo aparato se alude («Diçen fo cosa di ver / veyo entrar con tantos paxes»). El encomio se hace poniendo de relieve su formación jesuita, y destacando sobre otras cualidades la generosidad del prelado.

El segundo lleva el título de «Octavas cuio asumpto es un asueto que dio el Illustrísimo señor D. Ambrosio de Espínola y Guzmán meritíssimo obispo de Oviedo a los Artistas de la Compañía de Jhs. del collegio de Oviedo" (n. ${ }^{\circ}$ 5, págs. I58-16I) y consta de doce octavas reales. A partir del panegírico del obispo, el poema describe el convite con que este correspondió al homenaje que los colegiales de San Matías le rindieron el dos de agosto de 1667, para cerrarse a su fin con nuevas alabanzas al prelado. Se trata del primer ejemplo de poesía panegírica en asturiano, un indudable elemento de novedad sobre el modelo regueriano que, por otra parte, es seguido muy de cerca, y no solo por el común empleo de la octava real. En primer lugar, no parecen fortuitas las semejanzas parciales entre algunos endecasílabos como "Y cuntareye un casu que ye talu» (v. I5), que recuerda otros dos de Marirreguera («Un cuinto cuntaré que oí a mio güela» (Dido y Eneas, v. 8) y «Y cuntarévos coses tan estrañes» (Hero $y$ Lleandro, v. 17), o el que dice "Comieno hasta pusllar los tatinicos» (v. 49), que no oculta su parecido con aquel otro: «Comerín, claro está, sos bocadicos» (Hero y Lleandro, v. 315). Incluso se repite una voz solo documentada en Marirreguera («Una fía d'aquisti señoratu»), la voz señoratu («non tien que ver con isti señoratu Alexandro, non yega al so zapatu»), que pudiera ser forma humorística a partir de una variante ultracorrecta por señoritu. En todo caso, García de Prada exhibe un buen aprendizaje de las técnicas poéticas propias del barroco: el sometimiento al principio del decoro a través del tipo marco del diálogo figurado («Habla un amigo con otro») y el empleo de figuras retóricas como la metáfora («qui el torreznu, galán de los focicus»), el zeugma ("quando la rana pelu, il topo güeyos»), las comparaciones («nen con as aves la quayada yega, en 
blancures»), las enumeraciones en antonimia («qui al santiquín, al seriu, al bono, al malu») o el estilo sentencioso:

Que el sollibiase ell uno all otru hermanu,

Sempre a mi me parez per bon conseyo:

trabaye il rapacín, que ye llozanu,

si percansó de trabayar el vieyo,

llas veces del malatu faga il sanu,

que esto e mucha razón, ansí, facello.

Yo por fer la razón por il ausente,

Fixe al beber sos veces santamente.

Ejemplo este en cuyos versos finales se aprecia un insistente uso del registro humorístico, del que también Marirreguera supo hacer uso magistral.

En definitiva, el descubrimiento de este poeta quirosano y de su obra sirve de enlace entre la figura de Marirreguera y su proyección en los poetas del XviII, especialmente Torano de la Puerta, Fernández Porlei, Benito de l'Auxa y González Villar. También manifiesta la continuidad en el uso ceremonial de la lengua asturiana desde el Romance a Santa Olaya de Mérida pronunciado en la celebración de I639 hasta los villancicos que se representan para celebrar el nacimiento de los Infantes Gemelos, en $1784^{\circ}$, y el cantado en la función que hizo en 1789 el Cabildo de la de la Catedral por el ascenso de Campomanes al Consejo de Castilla ${ }^{10}$. Además la poesía panegírica de García de Prada antecede a otros

9 Es además el primer texto impreso en Asturias en asturiano. De su difusión y de su éxito relativo son prueba sus dos impresiones en Oviedo, llevadas a cabo por don Francisco Diaz Pedregal: una en la Descripción breve de las fiestas que hizo la Ciudad de Oviedo, con los plausibles motivos del feliz Nacimiento de los Infantes Gemelos Carlos, y Felipe de Borbón, y ajuste de la Paz con la Gran Bretaña, págs. 2I-23, otra al final de la Canción real a las fiestas, y diversiones publicas que hizo la ciudad de Oviedo, y sus respectivos gremios, en acción de gracias por los dos infantes mellizos, págs. 7I-74.

10 Letras que se cantaron en la noche de el dia 20. de Sepre. con el motivo del ascenso Yll. mo S.or Conde de Campomanes al Govierno del Supremo Consejo de Castilla de el que era 
poemas de este tipo cultivados por autores del XviII como el anónimo Un Asturiano da al Ilustrissimo Conde de Campomanes la enhorabuena, cuyas dos copias manuscritas se fechan en I78I.

\section{EL SURGIMIENTO DE LA LITERATURA EN ASTURIANO Y LA LITERATURA EN SAYAGUÉS}

Volviendo al Certamen de I639 en honor a Santa Olaya, al final de la Relación se decía que «acabadas las fiestas cierto Poeta las comprendió en un Romance» y se transcribía un poema en sayagués, imitación de otro de Quevedo, anotando que: «perdonen los asturianos que no va en su lengua, porque así la entenderán mas, y mejor». El mencionado autor de la Relación, el P. Andrés Mendo, llegado hacía poco de Salamanca, donde había permanecido ocho años (de I625 a I635, con dos años -de I626 a I628- de noviciado en Villagarcía de Campos), debía estar bien familiarizado con esta convencional lengua pastoril y bien pudiera haber sido el autor de dicho poema. En todo caso, prestó en su Relación una particular atención hacia estos dos dialectos leoneses, el sayagués y el asturiano, acogiendo poemas en ambas lenguas, a la vez que dejaba sin copiar otros en castellano o en latín.

Por otra parte, se ha pretendido establecer (Busto, 2000, pág. II7; Busto, 2002, pág. 94) un paralelismo entre la inclusión del sayagués en diferentes certámenes celebrados en el XVII, muy particularmente en Salamanca y la del asturiano en el de Oviedo de i639. El empleo de la lengua sayaguesa en este tipo de certámenes fue frecuente en Salamanca (en cuyos límites se halla la comarca zamorana de Sayago) durante la

decano. Funcion echa por el Yllmo. Cavildo de la Sta. Yglesia de Oviedo. Pusolas en Musica Dn. Luis Blanco Maestro de Capilla en dha. S.ta Yglesia. Reeditado hace pocos años a partir de una copia que perteneció a Fuertes Acevedo, que se halla en el Real Instituto de Estudios Asturianos (ms. F-IO7). 
primera mitad del XVII: así en las Fiestas, que hizo el Insigne Collegio de la Compañia de Jesús en $\mathrm{I}^{6} \mathrm{IO}^{\mathrm{II}}$ o en las Fiestas de la Universidad de Salamanca al Nacimiento del Príncipe D. Baltasar Carlos en $\mathrm{I}_{63 \mathrm{O}^{\mathrm{I2}}}$. Pero también fue empleado en otros lugares: un soneto «a lo pastoril sayagués» en Pastrana, en las fiestas de beatificación de Sta. Teresa en $1614^{13}$, un Romance de Luis de Benavente «en lenguage Sayagues» ${ }^{14}$, en Madrid en I650, etc. El recurso a emplear el habla sayaguesa había sido frecuente en el teatro pastoril del Xvi (en autores como el zamorano Juan del Encina o el salmantino Lucas Fernández) y también en los villancicos, pero fue decayendo a lo largo del xvir. La comparación de ambos fenómenos, el uso literario del sayagués y del asturiano (ambos dialectos del asturleonés), revela, sin embargo, grandes diferencias no sólo cronológicas (Busto, 2002, págs. 93-94). Hay primero que advertir que el término sayagués se aplica tanto al dialecto leonés de esa comarca zamorana como al dialecto salmantino o charruno (Pidal, 1962, págs. 34-35; Pidal, 2006-2008, págs. 5II-5I4), y comprende tanto textos que apenas tienen

"Se presentaron unas redondillas de Gómez Suárez de Figueroa, que merecieron un premio humorístico («doce sibilas guarnecidas») "por ser lenguaje tan cerrado que apenas se entiende», que comienzan: «Apareya dalmoçar, / moyer, fateyàme el fato».

${ }_{12}$ Se presentó una "glosa que compuso la Madre Isabel de san Felipe en sayagués, y aunque no la pedía el certamen, fue tan buena que no permitieron los juezes que quedas sin premio", que comienza (pág. 240): «Para enquellotrar mi grosa / sopongo en modo de engempro». También se presentaron unas redondillas de Manuel de Herrera Gallinato (págs. 265-268): «Señor Ri Dius vos mantienga / y a ñuessa Reina a demas».

${ }^{13}$ Compendio de las solenes [sic] fiestas que en toda España se hicieron en la Beatificacion de N. B. M. Teresa de Iesus fundadora de la Reformacion de Descalzos y Descalzas de N. S. del Carmen: en prosa y verso ... / por fray Diego de San Joseph religioso de la misma Reforma, Impresso en Madrid, por la viuda de Alonso martin [sic], I6I5, [5], 62 [i.e. 98], 232 h., [I] h. de grab.; $4{ }^{\circ}$. [El citado soneto se halla en la pág. 87 ].

${ }^{14}$ Ramillete de las flores, que del iardin del ingenio, regado con el rocio de la deuocion brotaron algunos de los elegantes y deuotos congregantes del Sansissimo [sic] Sacramento para cantar sus glorias en las festiuidades, que este año de 1650 ha celebrado su Esclauitud en el Conuento de Santa Maria Madalena de esta Corte, atadas por D. Ioseph Martinez de Grimaldo..., presentale al... señor don Iuan Francisco Pacheco, s. 1. [1650?], fols. 7r-7v. 
un colorido sayagués como el mencionado Romance sayagués burlesco de Quevedo hasta otros, como las seguidillas de Herrera Gallinato, donde «se trata de reflejar con exactitud el habla de Sayago» (Pidal, 2006-2008, pág. 5I2). En la ya muy castellanizada Salamanca del XVII, este autor se vio precisado a «explicar algunos vocablos sayagueses que, por serlo, eran menos conocidos [...] y tradujo sus redondillas en otro papel que presentó a los jueces (Lamano, ; 26), hecho que no sucede en Oviedo. La fijación de la variante «literaria» del sayagués, con solo unos pocos rasgos hipercaracterizadores que allanaban su comprensión, facilitó su empleo en toda España para remedar el habla pastoril. Algo muy parecido a lo que en la segunda mitad del Xvir estaba ocurriendo con los villancicos asturianos que se cantaban en las capillas musicales de muchas catedrales y conventos de Madrid y del resto del país.

El empleo del asturiano en contextos celebrativos resulta paralelo, como ya fue señalado (Busto, 2002, págs. 96-97), a lo ocurrido en Galicia, donde el idioma gallego se cultivó en alguna de las conmemoraciones que allí se hicieron ${ }^{15}$. Así en La Relación de las exequias que hiço la Real Audiencia del Reyno de Galicia a... la Reyna D. Margarita de Austria... descritas y puestas en stilo por Ioan Gómez Tonel (Santiago, por Joã Pacheco, I6I2), se incluyeron dos sonetos en gallego, uno de Joan Gómez Tonel (junto con siete en latín y siete en castellano también suyos) y otro de Pedro Vázquez de Neira (al lado de tres en latín, tres en castellano y otro bilingüe). Y también en las Fiestas Minervales, y aclamación perpetua de las Musas a la inmortal memoria de... D. Alonso de Fonseca (en Santiago, por Antonio Frayz, 1697), donde en su certamen o assumpto segundo, se proponía componer un romance gallego en 20 coplas $y$, aunque los textos premiados eran castellanos, se incluyeron

\footnotetext{
is Como en Asturias, en Galicia hubo celebraciones que no incluyeron poemas en gallego, como en los Juegos poéticos de la Universidad de Santiago de i662 dedicados a la Inmaculada Concepción.
} 
en la relación algunas composiciones en gallego de Joseph Gil Taboada (gramático), Bernardo Ballo de Porras, Joseph Guerrero (cura abad de Villauge en Lugo, natural de Madrid), Favián Pardiñas (deán de la Iglesia de Santiago), Juan Antonio Torrado (Lector de Artes en S. Francisco de Salamanca) e Ignacio Rodríguez.

Los certámenes barrocos dieron acogida a otras lenguas vernáculas como el vasco. Así, a la fiesta del Corpus del Pamplona de i6o9 acudieron poetas en euskera como Pedro de Ezcurra, Miguel de Aldaz y Juan de Elizalde, y también a la de i6ıo donde fue premiada y publicada una poesía en vasco. Asimismo en las honras fúnebres a Felipe IV, que rindió el Real Consejo de Navarra en en 1665 , fue incluido un poema en vasco del jesuita P. Francisco de Aleson (Villasante, 1979, pág. 97).

Es evidente que las justas y certámenes poéticos celebrados en este periodo propiciaron la heteroglosia no solo para el registro cómico o burlesco sino también para otros géneros como la poesía panegírica y celebrativa. No es descartable que, en el certamen ovetense de I639, el empleo del sayagués, que contaba con una más amplia tradición literaria, pudiese haber servido como modelo. Sin embargo, los poemas escritos casi treinta años más tarde por Juan García de Prada muestran que fueron los moldes cultos creados por Marirreguera los que ejercieron un influjo más profundo.

\section{Primeros TESTIMONIOS MANUSCRITOS DE POESÍA EN ASTURIANO}

Es cosa conocida la escasez de manuscritos antiguos de textos literarios en asturiano. La poesía de nuestros primeros poetas, Marirreguera y Francisco Bernaldo de Quirós, ha sido editada a través de copias de la segunda mitad del xviII, o de principios del xIx (Viejo, I997; Sánchez Vicente, 20I6). Algunos literatos del XVIII como Xuan Fernández Porlei, Bruno Fernández Cepeda o Carlos González de Posada, se ocuparon en 
transcribir, e incluso en editar, obras (o a veces solo fragmentos) suyos; sin embargo, de la mayor parte de estos testimonios, tan solo es posible ofrecer información sobre alguno de sus posesores ${ }^{16}$.

Habida cuenta de que los manuscritos de las obras de Marirreguera son todos del XVIII o del XIx, el mencionado manuscrito de la Colombina de Sevilla, que contiene dos obras del, hasta hace poco, inédito e ignoto Juan García de Prada, ofrece los testimonios literarios más antiguos entre el resto de manuscritos conocidos. Dicho manuscrito se ha fechado genéricamente como del siglo XVII, pues además de las piezas mencionadas, fechables en $\mathrm{i} 666$ y I667, contiene otras que remiten a los pontificados de Inocencio X (I644-I655), Alejandro VII (I655-I667) ${ }^{17}$, Clemente IX (I667-I669) ${ }^{18}$ y Clemente X (I670-I676).

En lo que atañe a los textos en asturiano, este nuevo testimonio ofrece, a través de sus grafías, indicios de interés que informan sobre la evolución histórica de la lengua asturiana (García Arias, 2017, págs. 196-202). Así, por ejemplo, aunque se mantienen las grafías medievales que distinguían entre consonantes sibilantes sordas y sonoras (jelus, anjel, gente / dixo, quixo, Alexandro; faze, nobleza, llozano / ñace, llercia, vicios; formosu, gasayosu, ansiosu / essu, essas, nuesso) los muchos casos de confusión de una grafía por otra (punjose, trajo, veces, noso, casso) muestran que la neutralización en favor de los resultados sordos ya se estaba produciendo o que ya era completa, si se considera a estas grafías como

${ }^{16}$ De estos, el grupo más numeroso lo forman los manuscritos que pertenecieron a José Caveda y Nava. El más importante de este conjunto es el manuscrito CA que contiene casi todo el corpus regueriano. También pertencieron a este fondo (conservado hoy en el archivo particular de don Joaquín García Samaniego) los testimonios de CB, CC, CD y CE, que contienen las fábulas de Marirreguera.

${ }_{17}$ Alexandro VII Pont. Optimo Maximo Eusebius Comes Truchsesius Collegii Germani et Ungarici alumnus felicitatem (h. I22 r.-I26 v.).

${ }^{18}$ Clementi D. P. Papae IX Epistola gratulatoria pro illustrissimo Dno. meo D. Ambrosio Ignatio Spinola et Guzman Archiepiscopo Compostellano (h. 7 r.-v.), etc. 
arcaísmos gráficos. Otros fenómenos lingüísticos resultan congruentes con el origen quirosano de su autor, procedente de una zona que se ha calificado como de transición entre el asturiano centro-meridional y suroccidental, donde se ha detectado metafonía por $-u$ y por $-i$ (Viejo, 200I, pág. 72), que también aparece en estos textos (ocupedo, isti, aquisti, aquil, vinti). Además, algunos otros fenómenos, propios hoy del asturiano occidental, estarían presentes en el texto como: las terceras personas de los indefinidos en -eno (fixeno), las formas del pronombre con asimilación del grupo consonántico (nuesso), etc. En definitiva, es evidente el interés lingüístico de estos poemas que, en ocasiones, parecen al mismo tiempo abandonar ciertos rasgos de su habla local para incorporar otros de tipo centro-norteño, que quizá procedan del estándar literario creado por Marirreguera (García Arias, 2017, pág. 202).

En todo caso, debe reconocerse la dificultad de llegar a conclusiones firmes cuando los análisis se hacen sobre un unicum, que no permite la comparación con otros manuscritos, en orden a establecer el grado de incorporación de variantes locales o el nivel de castellanización del copista. De ahí el interés que tiene, tanto para la ecdótica como para la lingüística del asturiano, poder contar con más de un testimonio, cosa que ya es posible para gran parte de los textos conocidos del XVII y XVIII.

En este sentido, de nuevo es especialmente valioso el testimonio del Pleitu ente Uviéu y Mérida que, como ya se ha dicho, fue editado a partir de la copia realizada por García Oliveros sobre la relación compuesta, a raíz del propio certamen, por el P. Andrés Mendo. Aunque extraída en el siglo pasado, la copia de García Oliveros debe ser tenida como mejor testimonio por ser también la más completa. Como ya fue señalado (Viejo, 2000, pág. 135), el otro testimonio antiguo, el ms. II97-II del Archivo de la Biblioteca de Montserrat, parece provenir del propio González de Posada, "probablemente’l mesmu qu’utilizó na ellaboración de les Memorias Históricas». Fue de esta edición de Posada, hecha en I794, 
de la que Caveda y Nava se sirvió para la suya, como prueba el verso 56 («Estremadura llibró»), si bien Caveda introdujo sobre aquella cambios a veces, importantes, como el añadido de cinco versos tras el primero, que en la edición de Posada figuraban como una línea de puntos. Las nueve ediciones anteriores a la de Xulio Viejo han seguido en general la versión impresa en la Colección de Caveda. Sin embargo, en un trabajo más reciente se nos informaba (Viejo, 2000, págs. 136-I37) de un rara impresión a cuatro columnas en el periódico Monte Gaudi de Pruaza (año I, n. ${ }^{\circ}$ I4, I2 dic. I894, pág. I), seguidora de una versión más cercana a la de la Relación del certamen. Esta versión impresa confirma ahora muchas lecciones de la copia de García Oliveros, pero también lleva a preguntarse en qué medida Oliveros pudo corregir en su transcripción algunas voces. Es lo que parece haber sucedido con la voz matanzúa (¿corrupción o derivado de matanzura 'matanza'?), avalada por el mencionado impreso de I894 y por la edición de González de Posada, que García Oliveros debió de corregir en matanza, a costa de convertir el verso en hipométrico.

El nuevo testimonio del Pleitu ente Uviéu y Mérida, editado por Justo García, obligará a partir de ahora a tomar este texto como base para una futura edición crítica que, como acabamos de mostrar, no deberá dejar de tener en cuenta las lecciones que ofrecen otros testimonios. Algo semejante ocurre con otras obras de Marirreguera a partir de los nuevos testimonios contenidos en el volumen manuscrito Poetas Asturianos, recientemente ingresado en la Biblioteca de Asturias «Ramón Pérez de Ayala». Hemos tenido oportunidad de destacar (Busto, 20I5, págs. 34-39) la importancia de este códice, que contiene copias de distinta mano de algunas obras de Marirreguera: la Fábula de Dido y Eneas (págs. 5-I6), el Entremés Bable del Ensalmador (págs. 4I-48) y el Diálogo entre Juan y Torivio, paysanos (págs. 49-64), más conocido como Diálogu políticu. En general, estos tres testimonios revelan una tradición textual bastante próxima a la del testimonio del ms. CA que fue tomado como base en la 
edición de Xulio Viejo y que es además el más importante de los que han transmitido obras de Marirreguera, pues contiene las fábulas de Dido y Eneas ${ }^{19}$ y de Hero y Lleandro ${ }^{20}$, el Diálogu politicu y los entremeses de L'ensalmador, de L'alcalde, y de Los alcaldes (este en una copia incompleta en su parte final) ${ }^{21}$. Sin embargo, un análisis más pormenorizado de cada uno de estos textos ha podido descubrir mejores lecciones en los testimonios de Dido y Eneas y de L'ensalmador, ofrecidos por este nuevo códice. Asimismo, el nuevo testimonio del Diálogu políticu, con ser también muy similar al del ms. CA, parece ser más antiguo por su mayor arcaísmo lingüístico (en él la palatalización del artículo es general).

Como casi todo el resto de los manuscritos que componen el códice de la Biblioteca de Asturias "Ramón Pérez de Ayala», las copias de estas obras de Marirreguera pertenecen a las últimas décadas del siglo XVIII, y lo mismo puede decirse de los manuscritos reguerianos del fondo documental de Caveda y Nava y de los que se conservan en la B. N. de España y en la Fundación Universitaria Española, todos ellos de finales del XVIII o principios del XIX. Por ello cobra particular interés el testimonio de un nuevo manuscrito desconocido hasta ahora, el P. V. I65 (Fondo antiguo) de la Biblioteca de Castilla-La Mancha, fechable muy probablemente en la primera mitad del XviII.

19 Dido y Eneas ha sido trasmitida también por los testimonios de $\mathrm{CB}$ y CC, que pertenecieran a la biblioteca de Caveda y Nava, y por el del manuscrito 3703 de la Biblioteca Nacional de España.

${ }^{20}$ La fábula de Hero y Lleandro se encuentra tambien en dos manscritos que pertenecieron a Caveda y Nava, los manuscritos CD y CE, a los que se añade una copia que perteneció al Conde de Campomanes, hoy en en la Fundación Universitaria Española, el ms. 34-A-20 [23/20]. Todos ellos sirvieron de base a la edición de Xulio Viejo. Al corpus editado cabría añadir un fragmento manuscrito (de 26 versos) que se encuentra en el ms. 9/4178 de la Biblioteca de la Real Academia de la Historia (Colección Vargas Ponce).

${ }^{21}$ En él se hallan también los poemas de Benito de l'Auxa («Los sueños de Nabucodonosor» $\mathrm{y}$ «Píramo y Tisbe») que fueron editados hace algunos años (Busto, 20I2). 


\section{UN MANUSCRITO DESCONOCIDO \\ DEL ENTREMÉS DE L'ALCALDE}

El manuscrito P. V. I65 del Fondo antiguo de la Biblioteca de Castilla-La Mancha lleva por título «Papeles varios en berso. Tomo 39» ${ }^{22}$. Su información catalográfica lo sitúa en el siglo "XVIII, post. I725»" año en torno al cual proceden otras piezas que lo integran ${ }^{24}$. El códice contiene además copias de obras de autores del xvir, como Antonio de Zamora ${ }^{25}$, o de la primera mitad del XviII, como Diego Torres Villarroel ${ }^{26}$.

El interés para la filología asturiana de este volumen manuscrito es grande, pues contiene la práctica totalidad de las poesías de Francisco Antonio Bernaldo de Quirós y Benavides. El primero en copiarse fue su poema en asturiano El caballu o (n. ${ }^{3}$ 6, fols. 97-IO4), al que siguen el resto de sus poesías en castellano, incluyendo entre ellas otra de su hermano José: n. 37 (fols. Io5r-IIIr), Pinta Benavides una muger («Excelsa ninfa de el hebro»); n. ${ }^{\circ} 38$ (IIIv-II3v) Retrato de una dama ("Oies tu, como te llamas?»); n. ${ }^{\circ} 38^{*}$ (II3v-II6r) Respueta de la dama («Arrogé desesperada»); n. ${ }^{\circ} 8^{* *}$ (II6r-II8r) Impugnacion de Campuzano a la Pintura Oies tu, como te llamas? ("Aunque nunca fui poeta»); n. 39 (II8r-I23r), Respuesta primera de Benavides a Campuzano («En argumento de Apo-

${ }^{22}$ Consta de [2] h., [3] h. en bl., 220 h. [4] h. en bl.; $4 \cdot^{\circ}$.

${ }^{23}$ Esta fecha está tomada de uno de los manuscritos, el n. ${ }^{\circ}$ 2I (h. 75): Avisos a un principe... 1725 ("Si sacrilego torpe desbocado»).

${ }^{24}$ Así la pieza catalográfica n. ${ }^{\circ} 48$ (fols. I64-I66v), Predicando el P. Matute el domingo II de junio de $1724 \ldots$ ("A dar el plazeme finos»), la n. ${ }^{\circ} 32$ (fol. 8ov), A la temprana muerte de Dn. Luis primero («No he de llorar por mas que con lamento»), datable en I724 o la n. ${ }^{\circ} 49$ (fols. I66v-I68), A las fiestas de Sn. Fhelix de Cantalicio ("Al santo mas excelente», algo posterior a 1713.

${ }^{25}$ Se trata, p. e., de la poesía n. ${ }^{\circ} 4$ (fols. I2-I7): Carta en que avisa Dn. Antonio de Zamora a su amigo Dn. Francisco Candamo de la muerte de la ... reyna. ("No son letras que son cifras»).

${ }^{26}$ Así la pieza n. ${ }^{25}$ (fol. 77), titulada Dice el pago que da el vulgo («Dicese de Quevedo que fue claro"). 
lo»); n. ${ }^{\circ} 40$ (I23r-I25v), Respuesta de Campuzano al antecedente ( Salio enfin, salio el papel»); n. ${ }^{\circ}$ 4I (I25V-I3Ir), Respuesta del autor a Campuzano («El arliquin de Palacio»; n. ${ }^{\circ} 42$ (I3Ir-I4Ir), Romanze a ...Luis dezimo quarto compuesto por ... Joseph Bernardo y Benavides («Gran Luis si de tantos triunfos»); n. ${ }^{\circ} 43$ (fols. I4Ir-I43r), En ocasion de aver concurrido el autor... a la cassa de Solores de Villaviziosa ("Divino halago del Ayre»); n. ${ }^{\circ} 44$ (fols. I43r-I44r), Quexase de una dama que se enamorase de otro (" Falsa enemiga tirana»). De todos estos poemas existen otros testimonios, aunque casi todos más tardíos, en especial las copias contenidas en el mencionado manuscrito Poetas Asturianos de la Biblioteca de Asturias «Ramón Pérez de Ayala» (Busto, 2015, págs. 33-34 y 47-56). Los dos últimos poemas eran hasta ahora desconocidos, aunque del segundo ya había sido transcrito su fragmento inicial. Se trata de los que en el catálogo llevan los números: 45 (fols. I44r-I49r), Respuesta â un Amigo que le persuadia dejase cierto galanteo («Una carta recibí»), y 46 (fols. I49v-I55r), Aviendo encontrado â mi señora la Marquesa de Liche en el Puerto de Paxares con mal temporal compuso Benavides el siguiente Romance («Sin referir quien adoro»). En general estos testimonios de los poemas de Benavides son más antiguos de los que se conocían, lo cual obliga a revisar ciertas cuestiones textuales sobre algunos poemas (Busto, 2015, 47-56; Busto, 2016, págs. 399-415).

El mencionado testimonio de El caballu es una copia escrita por mano distinta a la que copió el resto de las de Benavides. Sin embargo, precediendo a dicho romance, se encuentra la copia del entremés de L'Alcalde (fols. 82-96) de Marirreguera (vid. ANEXo) hecha por la misma mano que transcribió las mencionadas de Bernaldo de Quirós. Por tanto se trataría de una copia hecha en torno a I730, la más antigua de las que conservan las obras de Marirreguera.

Al principio del manuscrito figura su título: «Entremes a lo Bable de Anton de Maria Reguera» y, al lado, la relación los personajes que in- 
tervienen, donde ya se advierten algunos de los cambios que este nuevo testimonio presenta respecto al conocido hasta ahora del manuscrito CA. En efecto, el cambio del nombre de Xuliana por el de "Thorivia» no es el único elemento de novedad. El texto del manuscrito de Toledo representa una versión más amplia y completa, que aporta el exordio original del entremés regueriano e introduce digresiones como la de los orígenes del alcalde, Xuan Afonso de las Arbeyas, muy pertinentes para la caracterización del protagonista. Los 468 versos de este nuevo testimonio frente a los 442 del de CA dan idea del proceso de abreviación que sufren algunos pasajes como la narración de la seducción de Cecía, o la citación de la perra en el juicio, o los elogios de la cuñada del alcalde. Con todo, también se hallan casos en los que la versión de Toledo se olvida de algunos versos que sí aparecen en CA y que podemos suponer olvidos del copista de pasajes (uno o dos versos en general) que sí existían en el original. Por ello en la edición que ofrecemos se han tomado como base las lecciones del manuscrito de la Biblioteca de Castilla-La Mancha completándolo, en aquellos pasajes donde la rima o el sentido del texto lo exigía, con las que ofrece el testimonio del manuscrito CA.

La comparación de los dos manuscritos, alejados unos cuarenta años en su fecha de composición, revela también en el la Biblioteca de Castilla-La Mancha una mayor antigüedad en lo lingüístico. Ello es muy visible en el uso de los pronombres de $3 \cdot{ }^{\text {a }}$ persona en función de dativo, muy presentes en el manuscrito toledano que emplea abundantemente la forma -ye, desconocida por el testimonio de CA. El texto muestra una situación semejante a la descrita (García Arias, 20I6, pág. 20I) para los poemas de García de Prada donde también la forma más general es -ye para el singular y -yos para el plural (con algún empleo del singular en $-y$, como en el asturiano estándar actual). Concurrente con esta mayor antigüedad, destaca en lo fonético un más intenso arraigo de la palatalización de la $\mathrm{N}$ - inicial latina en [n], y también las formas palatalizadas del artículo (llo, llos, lla y lles) son más numerosas en el testimonio de 
Toledo, donde además se hallan presentes arcaísmos como el condicional se. La edición de L'Alcalde que cierra este trabajo toma como base este manuscrito del que se ofrece una edición paleográfica en la que se introducen muy pocas alteraciones que afectan a la puntuación, al uso de mayúsculas y minúsculas, y a la separación de palabras (aunque en estos casos se restituye la forma original en el aparato crítico). Asimismo la incorporación del testimonio del ms. CA en el aparato crítico, también en transcripción paleográfica, ha permitido detectar algunas lagunas y subsanar unos pocos errores en orden a ofrecer un texto de L’Alcalde más completo y coherente.

\section{BIBLIOGRAFÍA CITADA}

Alonso (1982) = Dámaso Alonso, «El doctor Manuel Serrano de Paz, desconocido comentador de las Soledades», Estudios y ensayos gongorinos, Madrid (Gredos), 1982 $2^{3}$, págs. 496-508 [I. ${ }^{\mathrm{a}}$ ed. Madrid (Gredos), 1955].

Busto (2000) = XUAN BUSTO CORTINA, «Una güeyada al sieglu barrocu n'Asturies: la vida lliteraria», en Antón de Marirreguera y el Barrocu asturianu, [Uviéu] (Gobiernu del Principáu d’Asturies), págs. II5-130.

Busto (2002) = XuAN Busto Cortina, «Antón de Marirreguera y el Barrocu lliterariu asturianu», en La lliteratura asturiana nel cuartu centenariu d'Antón de Marirreguera (conferencies y programa), Uviéu (Ediciones Trabe), págs. 9I-II8.

Busto (20I2) = Xuan Busto Cortina (ed.), Benito de l'Auxa-Antón Balvidares, Poesies, edición, introducción y notes de..., Uviéu (Ediciones Trabe), 248 págs.

Busto (2OI5) = Xuan Carlos Busto Cortina, «Un volume de testos de poesía asturiana de reciente apaición», Revista de Filoloxía Asturiana, I5 (2015), págs. 33-56.

Busto (20i6) = Juan Carlos Busto Cortina, «Tres poetas en el entorno de Feijoo: Bernaldo de Quirós, Martín Sarmiento y Lavandera Reyero», en I. Urzainqui, N. García Díaz \& R. Olay Valdés (eds.), Con la razón y la experiencia. Feijoo 250 años después, Oviedo, 2016, págs. 379-415.

Canella (1903) = Fermín Canella y Secades, Historia de la Universidad de Oviedo y noticias de los establecimientos de enseñanza de su distrito. Segunda edición, reformada y ampliada, Oviedo (Imprenta de Flórez, Gusano y Compañía), I903, 794 págs. 
Caveda-Canella (i887) = J. Caveda y Nava \& Fermín Canella y Secades, Poesías selectas en dialecto asturiano, Oviedo, I887 (ed. facs. Oviedo, I987).

Conde (2OIO) = JuAn CARlos Conde, «Sobre la identidad del copista del manuscrito del Livro da Monteria de Joâo I", en David Paolini (coord.), De ninguna cosa es alegre posesión sin compañia. Estudios celestinescos y medievales en honor del profesor Joseph Thomas Snow, Nueva York (Hispanic Seminary of Medieval Studies), 20Io, t. II, págs. 97-II4.

Fuertes Acevedo (i867) = Máximo Fuertes Acevedo, [inédito] Ensayo de una Biblioteca de Escritores Asturianos, s. 1., [1867], 2 vols. manuscritos que se conservan en la B. N. de España (sig. ms. 5649 y 5650 ).

Fuertes Acevedo (I885) = Máximo Fuertes Acevedo, Bosquejo acerca del estado que alcanzó en todas las épocas la Literatura en Asturias, Badajoz (Tipografía La Industria). A cargo de Felipe Mesía, 378 págs.

García Arias (20I7) = Xosé Lluís García Arias, "Dos nuevos poemes del sieglu XVII» [Reseña del libro de Justo García Sánchez, Aportaciones a la cultura asturiana del siglo XVII. Manuscritos inéditos de los años I665-I667. Dos poemas en asturiano (Oviedo, RIDEA, 20I6)], Lletres Asturianes, II6 (2017), págs. 195-202].

García Sánchez (20II) = Justo García Sánchez, Santa Eulalia de Mérida, Certamen Poético (I639), prol. Agustín Hevia Ballina, Oviedo (Asociación de Archiveros de la Iglesia de España), 20II, 203 págs.

García Sánchez (20I2) = Justo García Sánchez, El Doctor Tomás Serrano de Paz (Abogado y Catedrático Ovetense del siglo XvII), Oviedo (Real Instituto de Estudios Asturianos), 2012, I60 págs.

García SÁnchez (20I6) = Justo García SÁnchez, Aportaciones a la cultura asturiana del siglo XVII. Manuscritos inéditos de los años I665-1667. Dos poemas en asturiano, Oviedo (Real Instituto de Estudios Asturianos), 20I6, I7I págs.

Lamano (I9I5) = José de Lamano y Beneite, El dialecto vulgar salmantino, Salamanca (Tipografía Popular: Imp. de El Salmantino), I915, 679 págs.

Pidal (I962) = RAmón MenÉndez Pidal, El dialecto leonés, prólogo, notas y apéndices de Carmen Bobes, Oviedo (Instituto de Estudios Asturianos), 1962, I83 págs.

Pidal (2006-2008) = Ramón Menéndez Pidal, "Dialectos leoneses», Revista de Filoloxía Asturiana, 6-8 (2006-2008), págs. 499-514.

Ponce Cárdenas (20I4) = Jesús Ponce Cárdenas, «Manuel Serrano de Paz: deslindes para un perfil biográfico y crítico», e-Spania [en línea], I8 | junio 2014 [consultado el Is julio 20I7]. URL: <http://e-spania.revues.org/23607>. 
Posada (I794) = Carlos González de Posada, Memorias históricas del Principado de Asturias y obispado de Oviedo, Tarragona (por Pedro Canals), I794 [Ed. facs. Lluarca, 1972].

Posada (1989) = Carlos González de Posada, Biblioteca asturiana o Noticia de los autores asturianos, ed. prep. por M. Busto, Gijón (Editorial Auseva), 1989, I30 págs.

Roses-Jammes (1994) = Joaquín Roses Lozano \& Robert Jammes, Una poética de la oscuridad: la recepción crítica de las Soledades en el siglo XviI, Madrid (Tamesis), I994.

Sánchez Vicente (20i6) = Xuan Xosé Sánchez Vicente (ed.), Francisco Bernaldo de Quirós y Benavides, El caballu (edición anotada), Uviéu (Ediciones Saltadera), 2016, 80 págs.

SuÁrez (1959) = Constantino SuÁrez, Escritores y artistas asturianos. Indice biobibliográfico, Edición, adiciones y epílogo de José María Martínez Cachero, t. vII, Oviedo (Instituto de Estudios Asturianos), 1959, 496 págs.

Viejo (i997) = Xulio Viejo Fernández (ed.), Antón de Marirreguera, Fábules, teatru y romances, Edición, introducción y notes de..., Uviéu (Alvízoras Llibros), 1997, 319 págs.

Viejo (2000) = Xulio Viejo FernándeZ, «Fragmentos inéditos d'Antón de Marirreguera», en Antón de Marirreguera y el Barrocu asturianu, [Uviéu] (Gobiernu del Principáu d'Asturies), 2000, págs. I35-137.

Viejo (20OI) = Xulio Viejo Fernández, «Metafonía y contrametafonía en quirosán: pragmática, determín léxicu y morfosintaxis», Revista de Filoloxía Asturiana, I (200I), págs. 7I-II4.

Villasante (1979) = Luis Villasante, Historia de la literatura vasca, Burgos (Editorial Aranzazu), $1979^{2}$. 


\section{Anexo}

Edición de L'Alcalde a partir del ms. P. V. I65 del Fondo antiguo de la Biblioteca de Castilla-La Mancha ( $T$ ) y del ms. CA procedente del fondo perteneciente a Caveda y Nava.

Entremés a lo Bable.

De Antón de Maria Reguera

Personas que hablan en él:

Un Alcalde

Un escrivano

Thorivia
Cecilia

Don Juan

Llorente
Un mozo

Un mensajero

\section{(Dentro todos dizen:)}

Por muchos años sea alcalde

Xhuan Afonso de las Arbeyas,

gózela por muchos años,

Dios-ye la dexe goziar

(Sale el Alcalde y el escribano con la vara)

EsCRIBANO: El Señor Ayuntamentu me mandó bos entregás

Tit. T Entres [se añade la sílaba omitida] Atton [se añade el rasgo que falta] CA Entremes bable del Alcalde

A Personas que hablan en èl

El alcalde

Juliana

El escribano

Un mozo

Cecía

Llorente

Don Juan

Un mensajero

I-8 CA Esc. o: Alcalde, tomá lla bara. [reducidos a este único verso] 
esta vara per un añu

de Alcalde de la Hermandá.

Alcalde: ¡Pos ñon la quiero tomar!

EsCRIBANO: Pos será fuerza tomalla, que yo ñon la tó llevar.

AlCalde: Non la tó tomar, ñon me porfíen, ñon me obliguen que faga dessatinos, que yo quiero estar bien con mios vezinos.

(dale la vara)

EsCRIBANO: Veisla aý y si ñon querís tomalla bolbey a les elleciones a lleballa, que yo boy asestir a los señores que aunda están por fazer los rexidores (vase)

AlCALDE: Vibe Dios se acoyo y dexo la vara y ella me está diziendo «ñon me tomes, 20 mire, Señor, ñon cayga en tentaciones».

9 CA Pus ñon la tó tomar, volvé llevalla. [pus añadido] ıo CA primero me to ir pel mundo que tomalla [me tachado] II-I2 CA que quiero comer en paz lla mio proveza, [que tachado] / y ñon quiero quebraderos de caveza. [y tachado] / Escribano: Pos havéis de tomalla con todo eso. [de escrito sobre la línea] / Alcalde: Pos ñon la tó tomar solo por eso; 13 CA ñon me fagáis andar en desatinos, 14 CA quiero vevir en paz con mios vecinos. I5 CA Escribano: Pos si bos empeñais en non tomalla [escrito sobre la línea, que corrige si ñon queréis tomalla] $\mathbf{I} 6$ CA volvé a les eleciones a llevalla, $\mathbf{1 7}$ CA vò à àsistir à $\mathbf{1 8}$ CA que tuvía están por fer llos rejidores. [tuvía que se corrige sobre la línea que aun están] 19 CA Hilli, juro à Dios, se fó y dexó llabara 20 CA y ella mestá diciendo: «ñon me tomes». 2I CA Ñon me dejes, Señor, caier en tentaciones. 
Mas tómolla por ver si ye pesada: (levántala)

¡asiéntame meyor que la guiyada!

Pero, ¿quién avía de trayer ésta todu l’añu?

(pósala)

Buelvo a dexalla estar, llámome a’ngañu.

Pero, iquántos havrá que lla tomaren!,

y yo non sé, pardiós, si llo azertaren.

Bolbamos a llevantarla, brabu probechu

me as de dar, que será que ñon trabaye

en el tiempu que te empuñare

el mio pan y mio maíz con que me tó sostentar,

que el ser alcalde ye para señores

y ñon ye para probes abalidos,

que quanto más los suben a señores

entonzes se ben más aflixidos,

y así traten de ser alcalde que, o, ñon quiero

esta vara que-ye tengo miedo.

(Sale el escribano al paño)

22 CA Mas tó tomalla, por 22 bis CA (tómala, pasease) 23 CA Ella, voto à Dios, ma sienta miyor que lla guiada, 24 T lañu CA Mas, ¿quián andar conella tudu laño? 25 T angañu CA Ñon, ñon, yo vuelvola à posar, llámome angaño. 26 CA Más ¿quantos havrá aqui que lla tomaràn 27 CA y ñon se por Dios si lo acertaràn? 28-37 CA Escribano: Alcalde, muncho me fuelgo / que lla suerte vòs tocàs; / gozalda por munchos años. / Alcalde: ¿Que yè lo que tò gozar? / Escribano: Lla bara, digo, compadre. / Alcalde: Esa velda aý aú está; / tomalda vos si quereis, / que yo ñon la tò tomar. / Escribano: ¿Pos que razón dais parello? / Alcalde: Munches, compadre, tò dar. / Llo primero, que si un home / vestidu dautoridá / quier pasar à fer josticia / lluigu hi lo ande quitar / con recados de señores / ò del cura del llugar. / Lo segundo, que ñon puedo / el año que lampuñàs / cabar grano de centèn / ñin la hacienda trabayar. / Lo tercero, sà menester / à la justicia faltar / por contentar los siñores / que siñon despacharán / de la Audencia un Recetor, I y entonces el probe Juan, I en llugar de Juan de Dios / será Juan de Barrabàs. / No, amigo, yo aquí la dejo. $36 \mathrm{~T}$ deser $37 \mathrm{~T}$ que ye $38 \mathrm{CA} A$ isti alcalde faltai el sentido, 
EsCRIBANo Señores, aqueste Alcalde falta-ye el sentidu, con lo que otros se allegren él está aflixidu que algún ayre-ye dio o tubo miedo.

Falando está entre sí, falemos quedo.

AlcALDE Señores, habrá 40 años, poco más o menos, que se me morrieron los mios bisagüelos, xente de gran caudal y gran talentu que, por más que sea, yera xente de utru tiempu, yeren en esti conzeyu respectados y, por ser cabayeros, benerados. $\mathrm{Y}$ agora estoy aquí con esta vara y en coñozimientu que para gobernalla ñon tengo entendimientu.

\section{(Entra el escribano)}

EsCRIBANO Tenga bonos días, Alcalde amigu.

AlCALDE Secretario, sé mui bien benidu.

ESCRIBANO ¿Qué persadumbre ye’sa, mio amigazu?

AlcALDE Que esta bara me sirbe de embarazu y a quien lla trayer, sigún llo que estoy biendo.

Si un hombre fay xostizia, ye regurosu, si un hombre ñon la fay, ye perezosu,

39 CA con llo que otros salegren, illi está afligido). (À parte). 40-68 CA Hombron, lloque mira a istaño / de comer ño ha faltar / porque ñon safer fiesta, / que ñon vos hande llamar / yà veis de tener bon año. $40 \mathrm{~T}$ ayre ye $40 \mathrm{~T}$ bisaguelos $53 \mathrm{~T}$ yesà $55 \mathrm{~T}$ llatrayer 
si tien amigos, todo ye pedi-ye,

si ñon los tien, todo ye tura-ye,

y aunque tras de esto ñon aya residenzia

60

yo ñon sé cómo á complir con so conziencia

$\mathrm{y}$, sobre todo, trabayar en valde,

que también lo llamen bobería de alcalde.

ESCRIBANO Hombre, llo que mira isti añu

que comer non-y á faltar

65

porque ñon se á fazer fiesta

que ñon le embíe a llamar

y á de tener bon beranu.

Alcalde Con eso bien comerán

lla mio muyer y los neños,

70

par'eso baliera más

aprender el ofizio de gayteru

que también lu imbíen llamar

allegrándose con la fiesta

y páguen-ye por tocar,

y a mi ñon me paguen ñada.

Llo que quiero preguntar,

¿qué renta tien isti ofiziu?

EsCRIBANO Eso llo que travayar.

AlcALDE ¿Y qué trabayu á de ser?

80

$58 \mathrm{~T}$ pediye $59 \mathrm{~T}$ turaye $65 \mathrm{~T}$ non ya $70 \mathrm{CA}$ ñeños, $7 \mathbf{I}-88$ [faltan en $\mathrm{CA}] 7 \mathbf{I} \mathrm{T}$ pareso $75 \mathrm{~T}$ paguen ye $7 \mathbf{I} \mathrm{T}$ pagen [errata que se corrige] 
ESCRIBANO Si se vienería crellar

d'algunu dalgún vezín,

pidan bien o pidan mal,

prendellos a entrambos xuntos

y entonces ñon les soltar

fasta que den vien de sí.

AlCALDE Ye bon modu de medrar

y los conseyos son bonos.

¿Que yo tengo adevinar

de qué vibe el mio vezín,

si anda inquietu el capellán,

qué muyer entra en so casa,

qué ganado, cómo el pan,

si l'utru torga los gochos

y otres coses munches más

sin que por esto den ñada?

Esta vara se havía dar

a quien tubiés qué comer,

que isti ofiziu ño lu entiendu.

EsCRIBANO Pos bonu ye de azertar.

IOO

AlcALDE Vós fazéislu todu fácil

$y$, aunque ay gran dificultá,

$82 \mathrm{~T}$ dalgunu $86 \mathrm{~T}$ desí $89 \mathrm{CA}$ y yo $90 \mathrm{CA}$ de que vive el mio vecín, 9I-92 [Según CA, faltan en T] 94 T lutru CA si el utru 96 CA sin que 97 CA savia dar 98 CA a quian tuviès que comer, 99 CA yo isti oficio ño lo entiendo. IO० CA Pos bono està dacertar. IOI CA faceislo todo IO2 CA ancaya deficultá. 
llo que sé que con lla vara

me tó fer un folganzán

y, en acabando el xuzgadu,

ñingunu se á de acordar

de quando yo yera alcalde.

De vós sí, que ño acabáis,

que todos vos tienen miedu,

porque en buestra mano está

IIO

quien queréis que salga bien,

quien queréis que salga mal,

que como ñon sé firmar

vos sois xuez, vos sois alcalde

y sois todo llo demás,

que aunque yo mande una cosa

fuera lo mismo callar,

que escrivís lo que queréis

y ponéis al acavar

«mandólo así so merzé»,

I2O

y quiziáis ñon mandó tal.

EsCRIBANo Señor Alcalde, vosté

mui enpertinente está;

yo escrivo llo de razón.

AlcALDE Basta, se ño esquebrís más.

I03 CA Yo pienso que con lla bara IO4 CA folgazán Io5 T acabándose [que se corrige según CA para evitar el verso hipermétrico] CA yen acabando el juzgado Io6 CA ninguno sa dacordar Io7 CA yo era 109 CA y todo lo faceis vos, IIo CA pos en vuestra III CA quian $\mathbf{1 1 2}$ CA quian II3 $_{3}$ CA $Y$ deso lla culpa tien / el que yo ñon se firmar: II 4 CA con que vos sois el alcalde 15 CA y soys II6 CA y aunque yo diga uña cosa, II7 CA fora lo II8 CA esquibris llo II9 CA acabar 120 CA assíso mercê I2I CA y quizà 122 CA Vuesastè, señor alcalde, 123 CA muy emperteniente 124 CA No escribo 125 CA si ño esquibrís 
EsCRIBANO Asiéntese a fazer odenzia, que ay muncho que despachar.

AlcaldE ¿Conque an feme estar sentadu?, ¿aún esto tenemos más?

Lla xostizia á estar de pies

y ñadie la á de entornar.

Quien tobier que decir, salga.

EsCRIBANo Señora, entre para acá,

y trate de falar claro

y de ñon se acobardar.

(Sale Cecilia)

Cecilia El ñon me acobardar yá yo lo fago, mas si lo tó dezer oyan bostedes, coses son que sozeden a moyeres.

Señor, abrá seis meses que en Ubiedu, por mis pecados, serví a un cabayeru, servílo con amor y gran presteza porque yo siempre fui muy llinda pieza, salí de con él mui agradada y cobré sintilmente mio soldada, di en fazer para mí y tomar un tratu.

126 CA à fer audencia 127 CA cay muncho I28 CA Conque han feme estar sentado, 129 CA aún eso 130 CA lla josticia hastar en pie I3I CA y ninguno lo hastorbar 132 CA Quian tubies 133 CA paracâ 135 CA ñon tien que sà cobardar. $\mathbf{1 3 5}$ bis (Sale Cecía) 136 CA El ño mà cobardar $\mathbf{1 3 7}$ CA decer, oygan vustedes, $138 \mathrm{CA}$ que asoceden à muyeres $139 \mathrm{CA}$ habra, señor, seis años que en Uviedo $\mathbf{1} 40 \mathrm{~T}$ a un CA mios [...] caballero I4I-I42 [Según CA, faltan en T] I43 CA Salíme de con el muy I44 CA jentilmente I45 CA mi, tomar 
Perdonen que-yos doy isti mal ratu.

AlCALDE ¿Esto ye querellar o contar cuentos?

EsCRIBANo Señor, aquí entra el enfilar de los pimientos.

Cecilia Y escusando de razones, lo que digo, que un estudiante tropezó conmigo 150 una tarde en la Plaza, y combidóme y empezó a decir: «Señora, tome, yo quijera que foren d'oro les castañes». Y yo, xuzgando que era todu entrañes, respondí vozal y mui alguera deseava servillu si pudiera. Preguntóme el nombre y en qué cay bivía, cómo me llamava, y yo xuzgando que en eso lu servía falé de pe a pa. Golióme el fuelgu 160 y lluegu el corazón diome un ximielgu. Sacóme de la Plaza donde estava, que como havía allí otres ñon se reparava. Llevóme acia el Fontán y allí pescóme, y escusando razones empreñóme.

I46 T que y os CA que yos [...] rato I47 CA querella ò cuntar quentos I48 CA Aora entra el 149 CA Escusando razones, llo 150 CA que [...] comigo I5I CA comprò un uchavu de castañes, conbidome I52 y dijome: "señora, tome, tome, I53 T doro CA quixera que foren doro [en el ms. folgárame que, que se corrige sobre la línea] I54 CA Yo pensando que tudu era entrañes 155 CA arrespondij vozal y placentera 156 CA que deseaba 157-165 CA Meteòme en un portal y alli coieome / y, escusando de razones, esforceome, I59 CA mas yá [mas tachado y corregido] 160 T peapa 165 CA Aora ves aquí [Aora ves tachado y corregido] 
Yo así tó crellar criminalmente, si ay llugar en derechu.

AlcALDE Por Dios, la relación foy de provechu.

Y vós, ¿`cómo bos llamáis?

Cecilia

Señor, Cecía.

Alcalde Zecía, Zecía, Cezina avéis de ser y vien curada.

170 ¿Deseáis ser alcalde, camarada? (al escribano)

EsCRIBANO Yo para mi bastante ofizio tengo.

AlcaldE Ea, pues según eso, a lo que bengo, bengo, ¿Y aora qué me pide la Cecía?

Cecilia Señor, que el estudiante se foy para Castiya, que embíe tras d'él ministro mui deprisa.

AlcALDE Xuro a bríos, que el cuento ye de risa, que porque el utru picarón desbergonzadu andubiese con su gatiyu llevantadu, ¿tengo yo despachar con mi alcaldía I80 tras él a los reynos de Castiya?

I66 CA yansi me vengo a crellar creminalmente 167 CA derecho $168 \mathrm{~T}$ deprovechu CA Par Dios, lla relación fo de provecho 169 CA Y cómo vos llamaìs muyer [muyer tachado] 170 CA Cecina habís de ser, y bien [cecina corrige una palabra ilegible] I7I-I73 CA ño estobieres quiza tan maltratada $\mathbf{1 7 4}$ CA ¿Y que me pide aora lla Cecia? 175 CA Señor, quel estudiante se fó para Castía, $176 \mathrm{~T}$ del CA que unbie tras dilli ministros muy à prisa $\mathbf{1 7 7}$ CA Vive Dios quel quento 178 CA Conque, porque $\mathbf{1 7 9} \mathrm{T}$ gatiya [errata que se corrige] CA ande con el gatío llebantado, I80 CA yo andar con mio I8I CA despachando ministros cada día 
¿Tengo de de ser alcalde? ¡Tomá un cuerno, sea alcalde el demonio del infierno! ¿El demonio deparóme tal ofiziu?

EsCRIBANo Asiéntese, señor Alcalde, y tenga xuiziu.

AlcALDE Que con esto ayga prudenzia

EsCRIBANO Asiéntese, por Dios, tenga pacienzia.

AlcALDE ¿A qué me tó sentar, escrivanu?

ESCRIBANO A fer odenzia y tratar de despachar aquesta moza.

AlCALDE ¡Ó, qué falta fay una coroza a semexante xente! 190 Pero, ya que pedís el que me siente, tó fazello aunque sea contra mio gusto. Bení acá, decíme lla verdá como ye xusto. ¿Vos sós de isti conzeyu?

Cezilia Sí, Señor, y soy fia de Afonso del Caleyu, 195 su amigo de buesté y algo pariente.

I82 [Según CA, falta en T] CA Tengo de de ser alcalde? sese [escrito sobre la línea] I83 CA y sía alcalde un demonio 184 [falta en CA] I85 CA Escribano:Alcalde, decencia tené y tené xuicio, I que lo requier asi buestro egercicio [decencia tené y añadido sobre la línea] [que lo requier asi buestro egercicio añadido bajo la línea] I86 CA Quieren que yo non pierda la pacencia [yo añadido bajo la línea] 187 CA Asientese y ñon tenga negligencia. I88 CA Aquè me tò sentar? À fer audencia 189 CA $Y$ trate despachar aquesa moza $190 \mathrm{CA} ; O$, que falta hi fay una coroza / à semejante jente! 191 CA que pedis el que masiente 192 CA anque sía contragusto; $193 \mathrm{CA} /$ decíme lla verdà como yè justo $194 \mathrm{CA}$ Vós soys disti conceyo 195 CA Yò sò fia de Afonso del Caleyo 196 CA amigo de vusté y 
Alc ALDE Aquí entra lla llocura de la xente, que viendo a un hombre en semexante puesto tien pariente a diestru y a siniestru, pero en acavándose el xuzgadu 200 yá tudu el parentesco está acavadu. Ven acá, ¿qué ora sería quando empreñasteis?

Cezilla Señor, sería allí a la oración.

AlcALDE Pos, ¿ñon rezasteis? Tratá de rezar, fer penitencia, que ñon con bos sola á ser la odenzia.

EsCRIBANo Aquí el señor don Juan tien que dezir.

Cezilia Duélase de esta pobre, por so vida.

AlCALDE Aora tenéis vós meyor salida.

Ý tratar de parir y entrar por ama, llevaránbos les sopes a lla cama, $2 \mathrm{IO}$ y si lla ñazión ñon muere de repente y si estáis en Oviedo a lo presente, la plantaréis en una iglesa o combentu. Ý quitavos de ay lluegu, al momentu. (vase Cecilia)

I97 CA Mira aquí la llocura de la jente [Ahora ves aquí tachado y corregido] 198 CA en viendo à un home en semeyante puesto 199 CA ya tien parientes à diestro y à siniestro [ya tachado] $200 \mathrm{CA}$ mas en acabandose el juzgado 201 CA tudo el parentesco và acabado. 202 CA Y volviendo à nuestro quento I ¿À que hora vos juntastes? 203 CA Ala ora de la oracion. 204 CA ¿Pos, segun eso, ñon rezastes? / Andà à rezar, fe penitencia. 205 CA So, secretario, cese aqui la audencia. 206 [falta en CA] 207 CA desta probe 208 CA Aora yà teneis miyor salida 209 CA parir, entrar 210 T alla CA lles sopes 2II CA non fuere derepente $2 \mathbf{2} 2$ CA y sistáis en Uviedo a llo presente 213 CA lla pondreis à lla puerta dun convento. 2I4 CA ;Ca! Quitávos dàhi lluigo al momento. I Escribano: Ella va despachada bien de valde. 
(Sale don Juan)

Don Juan Tenga so merzé mui bones tardes.

AlcALDE ¡Xesús, Xesús, tantu favor para la de tarde!

Diga el señor don Juan.

DON JUAN Pues, señor, digo:

Abrá dos días que tropezó conmigo

Xuan Afonso, el de la Quintana,

y siendo mi calidá yá tan anziana, sin mirar que lo ohía mucha xente se dexó llamar Xuan públicamente.

AlCALDE Y vós, ¿cómo bos llamáis?

DON JUAN Señor, don Juan.

AlcALDE Y él, ¿cómo bos llamó?

DON JUAN Xuan solamente.

AlcALDE ¿Nonon ben en qué estadu está lla xente, por ónde el demonio entra a fer so ofiziu?

215 CA Buenas tardes tenga usted, señor alcalde. 216 CA Jesus, señor don Juan, tanto favor para esta tarde 217 CA ¿Qué manda el sò don Juan? 218 CA Pues, señor, digo 219 CA que habra dos días tropezó commigo 220 CA Afonso Suare, aquel de 22I CA calidad yà tan anciana 222 CA sin reparar lo oýa mucha gente 223 CA se dexó llamar Xuan públicamente / Testigos tengo desto, no lo dude. 224 CA Tenè, tenè. Pos vós, ¿como vos llamais? [ $Y$ vós corregido sobre la línea en Pos vós] 226 CA Y, ¿cómo vos [Y illi, ¿cómo tachado illi] 227 CA Juan 228 CA ;Non miren enquestado està la jente!' 229 CA jPor aù entrò el demonio àfer soficio! 
Señor don Juan, por Dios, que tenga xuiziu.

DON JUAN Trate de fazer jostizia o daré quexa, porque ñin fay xostizia ni la dexa.

AlcALDE ¿Qué xustizia tó fer?

DON JUAN La que quisier, porque si ñon la fay como se deve yá pondremos enmienda.

Alc $A L D E$ Señores, ¿ay por ahý algunu que lo entienda? Señor don Xuan, ¿buesté qué pide en suma?

DON JUAN So secretario saque aý una pluma $\mathrm{y}$ deme un testimonio de la xustizia que fay el seor alcalde, que ñon-ye mandan trabaiar de baldre.

EsCRIBANo Pos el señor don Xuan é de bona xentte.

AlCALDE ¿Acaso por ventura digo yo que miente? Yo bien conozí a sos antepasados, pero ñon tenín doñes vinculados,

$230 \mathrm{CA}$ que tenga juicio 23I CA hacer justicia, ò darè queja, $232 \mathrm{CA}$ pues ni bien la hace, ni la deja. 233 CA josticia 234 CA Laque quisiere 235 CA y si no la hace como sedeviere 236 CA emmienda

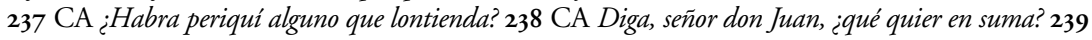
CA Secretario, saque Vuestra Merced una pluma 240-24I CA y deme por fee lo que hace el alcalde 242 $\mathrm{T}$ ñon ye CA pues no le mandan trabajar de valde. 243 CA Juan, yè dè bona jente. 244 CA Pos por [...] que $245 \mathrm{CA}$ Yo conocì muy bien à $246 \mathrm{CA}$ dones 
que so buelu yera hombre mui onrradu, tamien plantaba al hombro so forcado, baxábase tal vez soplar el fuego y agarraba del rabu del llaviegu, 250 hiba al molín si acaso se ofrecía y, con todo eso, nunca romería facía casu d'illi, ni n'otres partes. Pero vení acá, ¿d'ú traxisteis estes cartes? ¿O..., diérovos el Don? ¿Vós ñon estudiasteis?

¿Nunca fuisteis dotor, nin sos lletradu?

¿Nin fosteis oposetor ñin prebendadu?

Pos a ñingunu d'estos puestos allegasteis.

Vení acá, ysi don, d'ú llu pescasteis?

Buesu padre que vive todavía, 260 ¿llámase acaso Don? ¡Qué bobería!

Non mirar pa llos pies, fer llo quel pabu por ño andar con el rabu llevantadu.

Hý quexavos de mi a d'u quixereis, en Ubiedu, en Vayadulí o nel conzeyu,

y ñon tengu paciencia, aquí llo dexo. ¿El demonio deparóme tal ofizio?

247 CA que sò agüilo era un home honradu 248 [Según CA, falta en T] 249-250 CA y agarraba del rabo del llabiegu, / vajabase tal vez soplar el fuebu [con el orden alterado] 25I CA iba al molín sacauso sòfrecia 252-253 T peru por eso en una romería / fin muchu casu del, y en otres partes [se sigue la lección más congruente que ofrece $\mathrm{CA}] 253 \mathrm{Ca}$ dilli nin otres $254 \mathrm{~T} d u \mathrm{CA}$ pero vos ¿de hù trajestes eses cartes? / ¿O diérovos el don? 255 CA O..., diérovos el Don [falta en T y se restituye en la edición] CA Vos nunca estudiastes, 256 CA nunca fuestes dotor, ñin sois lletrado, 257 CA ñin sois opositor, ñin prevendado $258 \mathrm{~T}$ destos $\mathrm{CA}$ si à ninguno destos puestos non llegastes, $259 \mathrm{~T}$ dullu CA deceme: ¿aquisi don ahú lu pescastes? 260 CA Vuestro padre que vive toda via $262 \mathrm{~T}$ pa llos CA mirar muy bien pallos pies, fer llo quel pabo 263 CA por ñon andar con el rabo llebantado 264-265 CA y quejavos de mí al consejo, $264 \mathrm{~T}$ du $266 \mathrm{CA}$ yo non tengo pacencia, aqui lo dejo $267 \mathrm{CA}$ ¿Deparòme el demonio tal oficio? 
ESCRIBANO Alcalde, ¿vós qué facéis? ¿Non tenéis juicio?

DON JUAN ¡Por Dios, que está buena la alcaldada!

AlCALDE ¿Qué ye lo que mormura el Don Ño Ñada? 270

¿Quier que-ye dé el don al don Virote?

Puede ser-ye lu dé con un garrote.

EsCRIBANO Mirá, alcalde, que estáis faziendo odenzia.

Alcalde Ñon me acordava, en Dios y en mio conzenzia.

Secretario, bamos despachando,

que lo que mira oy tendré pazienzia, pero mañana faga utru la odenzia.

(Sale Thoribia)

ThORIBIA Dios me guarde a so merzé.

AlCALDE Así faga a vós. Falá y decí llo que queréis.

ThoribIA Señor, yo qué quier que quiera...

AlcALDE ¿Pos a qué entrasteis acá?

268 [Según CA, falta en T] 269 CA que está buena la 270 CA ¿Que mormura el don Don, el don No Nada? 27I T queye CA ¿Querra que hilu dè yo el don, virote? $272 \mathrm{~T}$ ser ye lu CA ser que hi ludè conun 273 CA questais faciendo audencia. 274 T meacordava CA Non macordaba en Dios y en mio concencia. 275 CA So, secretario, vamos 276 CA que llo que mira; huè tendré pacencia, 277 CA la audencia. 277 bis CA (Sale Juliana) $278 \mathrm{CA}$ Juliana: Dios guíe à sò mercè, señor alcalde. $279 \mathrm{CA}$ Decí lloque queréis, que yà yè tarde. 280-288 CA Decí, ¿aque entraste aca? / Jul.a: Señor, yo por ñon cansar / cuntaré mio relacion / si me quieren escuchar: / ayer nuichi de mañana / viniendo del argumal / Antoñon el de Maruja 
ThoribIA Señor, vengo aquí preñada.

AlcAlDE Bien se conoz, que llo estáis.

¿Y qué bais dezir en eso?

ThoribIA Señor, el que so merzé

ha de vengar la injuria que se me fexo,

porque el fíu de Xulián,

estando yo descuidada,

me empreñó sin más ñin más.

ALCALDE ¿Empreñasteis por descuidu

ensin poner ñin quitar?

Me parezéis unes mozes

que anden allá ena ciudá

que dizen fan para sí

y saquen ysi xornal.

¿Y vós entonces aú estabais?

Thoribia Yo, señor, estaba en casa

y él benía del argomal.

AlcALDE ¿Abís estar en Arxel?

Non bos hiva a pescudar

300

si ñon si estaveis presente

al tiempu del empreñar.

289 CA Mes forzò sin más ñin mas 290 T Emprenasteis [errata que se corrige en la edición] CA ¿Esforciótte por descuydo 292 CA Me parecéis unes moces 293 CA que haviten una ciudá 294 CA que enfaciendo para si 295 CA saquen aquisi jornàl. 296 CA à hù 297 CA Jul.: Señor, yon casa. 298 [falta en CA] 299 CA ;Havis estar en Arjel! $300 \mathrm{CA}_{¿} \mathrm{Yo}_{\mathrm{o}}$ vos iba apreguntar $30 \mathrm{O}$ CA si vos estabais presente $302 \mathrm{CA}$ al tiempo del esforciar? 
ThoribIA Señor, eso sería fuerza.

AlcaldE Llegabos más para acá.

Yá tenéis bona barriga.

¿Y de quántu tiempu estáis?

ThorIBIA Señor, d'unos cinco meses.

AlCALDE ¿Y podéis xustificar

que estáis preñada de él?

Thoribia Señor, él lo á declarar,

porque antes me dio palabra

primero que me esforciás,

y yo después di-y a él

una sortía que tray.

AlCALDE Según eso está axustadu

y puesto como ha de estar.

¿Y él aora qué vos diz?

ThorIBIA Señor, él, que ñon quier casar conmigo.

Alc $A L D E$ ¿Pos qué razón da para eso?

303-305 CA Yà estáis muy bien abultada 306 CA quanto tiempostais $307 \mathrm{~T}$ dunos CA dunos quince 308 CA jotoficar 309 CA quel embarazo yè dilli? 310 T adeclarar CA Xuliana: Farèlo yo declarar, $3 \mathbf{I I}$ CA pos medio mano y palabra 312 CA mesforzàs 313-314 [faltan en CA] 313 dij o dý [que se corrige] 315 CA ajustado 316 CA hà destar 317 CA Y illi aora 318 CA Jul.:Que comigo ño hà casar. 319 CA ¿Y que razon dà parello? 
Thoribia Señor, la razón que da

foy que una mañana destes

pasó el cura del llugar

y me dio los bonos díes.

Puede crer que no ebo mas.

EsCRIBANo Pos eso ñon foy delitu.

AlCALDE Secrettario, sí fo tal, que a llos cures ñon-yos toca

dar llos dis por el llugar,

tóca-ios el dar lles fiestes,

arrimados al alttar.

¡Llíbreme Dios de muier

que siempre fay mal,

que para Dios fazella bon

á tornalla a fabricar!

Poné aý, que tengo prisa,

que la traten de emplumar

en posando lla barriga,

después lla desterrarán

cien mill llegües en contornu

por que escarmen lles demás,

321 T destes CA ye cuna mañana destes $322 \mathrm{CA}$ de llugar $323 \mathrm{CA}$ los bonos dis $324 \mathrm{CA}$ [Según CA, falta en T] 325 CA fo delito. 326 CA Secretario 327 T ñon yostoca CA callos cures 328 CA dar bonos dis pel llugar $329 \mathrm{~T}$ tocaios $\mathrm{CA}$ tocayos $330 \mathrm{CA}$ à laltar 331 CA de muyeres $332 \mathrm{CA}$ can si llo diz el Misal 333 CA que para Dios felles bones 334 CA à tornalles flabicar / Escriba el sò secretario / porque un auto quiero dar. 335 CA Lo primero que yo mando $336 \mathrm{CA}$ que la traten de emplumar $337 \mathrm{CA}$ yen posando llabarriga $338 \mathrm{CA}$ dempues $339 \mathrm{~T}$ llegues $\mathrm{CA}$ cien mil llegües en contorno $340 \mathrm{CA}$ porquescarmen 
porque empreñados por descuidu

huvo desde Adán acá

más que de yerbes en campu

$y$ de arenes ena mar.

Y utrusí, que quando para

llo que ena barriga tray

que se obligue se sea machu

porque femes fartes ay,

que la mitá d'elles sobren

y aún pienso que sobren más.

ThorIBIA Señor, duélase de mi.

AlcALDE Tendrélu como de un can.

ThorIBIA Repare que estoy preñada.

AlcALDE Y si lo estáis, xuro a tal que tengo desempreñabos.

Tratá de ñon me falar más, que si aora fay veinte años se empezaren a castigar los empreñus por descuydu, pudiera ser ñon se fayaren

34I CA porque esfuerzos por descuydo 343 CA mas que de yerbes ños campos $344 \mathrm{~T}$ en amar CA $y$ darenes eña mar; 345 CA Otro sí, que quando parìa 346 CA lloque ña barriga trai 347 CA quesòbligue que sia macho $348 \mathrm{CA}$ porque $349 \mathrm{~T}$ delles $\mathrm{CA}$ y la 351 CA dólgase 352 [falta en CA] 353 CA questò $354 \mathrm{CA}$ lostâ, juro $355 \mathrm{CA}$ tengo yo desfer lo fecho. $356 \mathrm{CA}$ Trata ñon me faltar mas, 357 CA que si agora fay veintaños 358 CA comenzaren castigar 359 CA los desfuerzos por descuydo $360 \mathrm{CA}$ entòs ñon savincontrar 
tantos neños nes iglesies

como se suelen fayar.

Thoribia Pues, mande prender al mozu.

EsCRIBANo Señor, el mozu aquí está.

AlCALDE Mandá que salga aquí lluego.

(Sale el mozo)

EsCRIBANO Si, ó, manzebu, bení acá

AlCALDE ¿Qué quitasteis a esta moza?

Mozo Señor, ¿qué-y avía de quitar?

AlcaldE Pues, ¿qué ye llo que pedís?

Thoribia Señor, el que-y mande casar conmigo, 370 pues me empreñó.

Mozo ¿Yo empreñate? ¿Yo empreñate?

Xuro a tal que mientes mui frescamente aunque lo quieras provar.

361 CA ñeños ñes 362 CA como suelen afayar. 363 CA Pos [...] mozo 364 CA señor, caqui fuera está 365 CA lluigu 365 bis CA (sale) 366 T Sio CA Sio, mancebo, venì acá 367 CA quitastes $368 \mathrm{~T}$ que ý CA hi habia 369 CA ¿Pos aora que pedis? 370-37I CA Jul.:El que hi mande casar / comigo, pòs me esforzò. 370 T que ý 37I T emprenó [olvido del rasgo que se corrige] 372-374 CA Manc.: ;Yo esforzate! Jesus, Credo, / ñon me lo podras provar / anque tengues mas testigos / cay en todo larrabàl. / ¿Yo esforzate? ¿Yo esforzate? / ¿Pensarà el demonio tal? 
ThorIBIA ¿Miento yo?, mal perxurado,

cómo el diablo t'á llevar.

Non te acuerdes quando en casa

me entornaste para atrás.

Entonces ñon decís eso,

mal aya quien bos lo da. (Vase)

AlCALDE Si ñon tienes más probanza

ñon tengo que sentenciar

pos ansí lo diz Tortosa

en el capítolo tal,

Y llo canta'nsí a lla lletra:

ninguno puede casar

sin presencia de testigos.

Siendo assí dequí marchá.

ESCRIBANO: ¿Está peri hi Llorente?

(Sale Llorenti)

LLORENTE Si, ó, Secretario, aquí está

a vuestro servicio.

$\mathrm{A} L C A L D E$ ¡Ay tal!

¡Y cómo viene reberente!

375 CA Juliana: Tu mientes, grande embustero $376 \mathrm{~T}$ ta CA tallevar 377 CA Non tacuerdes quandoncasa 378-380 CA dijiste tà vìs casar / comigo y ñon tubies pena? / Yes un perjurado tal. 38I [Se sigue la lección de CA] T Si ya ño ay más residencia, 383-392 [Según CA, faltan en T] 385 CA cantansi alla 389 bis [Según T, en CA: (sale)] 


\section{EsCRIBANO ¿YY aora qué pide Llorenti?}

LLORENTI Señor, so mercé me lo oyrá

falando con devido acatamiento

de la vara del rey del reximiento

de les toques honrrades, de les viudes, solteres y casades, del misal, manual, isopu y calderu, y del Camín Real que avía de reserbar primeru me vengo a crellar criminalmente de la perra del cura.

AlcALDE Pos Llorente, esa causa ñon pasa ante el juez pola indecencia, el cura lo habrá de remediar por so concencia; pero como tanto la avéis reservado, xuro a bríos, pensé que venía cagado, pero yá que llo ponéis en nuestra mano a prueba llo reciva el escribano.

EsCRIBANO Si ye puya, que ñon valga.

AlCALDE Nunca ello de la voca se bos salga, facey lla relazión, ñon perdáis xera.

393 CA ¿Que yè lloque me pide el so Llorente? 394 CA Yà so mercè llo verâ: 395 CA hablando [...] acutamiento [corregido en acatamiento] $396 \mathrm{CA}$ de lla bara del rey y rejimiento $397 \mathrm{CA}$ y delles toques honrades 398 CA de todes lles bieyes, solteres y casades, 399 CA soplo y caldero 400 CA del camín rial, cavia decer primero, 40I CA criminalmente 403-405 T Pues Llorenti, esa causa ñon pasa / por esta odenzia de xuez [se subsana la laguna del texto a partir de la lección de CA] 406 CA tanto haviais 407 CA ciertamente crè̀ veniais cagado; $408 \mathrm{CA}$ mas yà que lo pones ena mio mano $409 \mathrm{CA}$ recibia el esquibrano 4IO CA Alcalde, si yè 4II CA lla boca se vos $4 \mathbf{1 2}$ CA facè lla relación, ñon perdiais jera 
LlorENTI Pos el casu pasó de esta manera:

Ayer nuichi umbié a Uviedo lla mio Antona

(y quando vieno yera yá a deshora)

con un cesto, un puchero y la farrica,

que me traxés de saín una puchera

que llo mide ruinmente lla estanquera.

Púxela tras de el fuego en un poyu,

fuime para el corral y lluego, al punto,

oyo la medula de llingua, y por mios males

420

beo la perra llamiendo los caxales.

Coyo un forcado, salgu tras la perra

y ñon la pude fayar en mar ñin tierra.

Aora miren si ye razón y cortesía,

pase el cura con esto cada día,

y así mande que él o la cadiella

me paguen el saín, aquesto ye mio crella.

AlCALDE A la perra se citte en nombre d'esta parte

o se emplaze por pleyto retardado,

que yo ñon pienso echame con lla carga.

EsCRIBANo Según eso, este pleyto ba a la llarga, porque perra que está duecha a comer bolles ye de gran perxuicio pa les olles.

4I3 CA Pos el causo pasò desta manera. 4I4-4I6 T Umbié à Ubiedo lla mio María / con so cesta y so xarrica, [se subsana la laguna del texto a partir de la lección de CA] 4I7 CA que traìa de 4I8 CA que mide sin concencia lla [que la mide, con la sílaba la tachada] $4 \mathrm{I9}$ CA Punjolo tras del fuibu sobre un poyo 420-42I CA y por mios males / vi la perra del cura rellamber los cajales. 422 CA Coý un forcado, salgo tras llaperra $423 \mathrm{CA}$ ñon la pude pescar à mar ñin à tierra, $424 \mathrm{CA}$ yansí, mire si yè razon ò cortesìa $425 \mathrm{CA}$ pase el cura con esto cada día 426 CA yansi mande quel cura ò so cadiella 427 CA saìn, yesta lla crella. 428436 [faltan en CA] $428 \mathrm{~T}$ desta $432 \mathrm{~T}$ porque perra \{que perra\} [se corrige la expresión reduplicada] 
AlCALDE Pos lluego el pleytu está entabladu:

saín, xarrica, el cestu, el poyu, el corral y el forcadu. 435

LlorENTI Aqueso propio ye pinttu y paradu

(Vase)

AlcALDE Pos mando que al instante

se entregue la perra al querellante,

el qual-ye meta sin embarazu

u se-ye remata el espinazu

una mecha de estopa bien torzida

y cuidado que la tenga enzendida

todu el tiempu que durar la grasa,

y que la mecha sea gorda, llisa y llasa,

porque si da llugar que salga el viento

llapiaráse el saín en un momentu

y si acaso el ayre ye corrutu

ñon podréis de la perra sacar fruto.

EsCRIBANO En mio vida oy tal disparate.

AlcALDE ¿Pos qué queréis, Escribano, que la matte?

450

Matayla vós, y mucho ñoramala,

437 CA calistante 438 CA Se hi entregue lla $439 \mathrm{~T}$ qual ye CA à la qual hi meteràn sin embarazo $440 \mathrm{~T}$ se ye CA haù sei remata elespinàzo 44I CA destopa bien torcida 442 CA y esta mecha hastar bien encendida 443 CA todol tiempo que durâs 444 CA y quenta que sia gorda 445 [falta en T, se subsana el verso que falta a partir de CA] 446 CA llaparàse el saìn enun momento, $447 \mathrm{CA}$ y si acauso el ayre yè corruto $448 \mathrm{CA}$ della perra $450 \mathrm{CA}$ ¿Que quereis, esquibrano, que llamate? 45I CA Matalda vos enora mala 
que a mi bástame echa-y aquesta cala, que amechando vien la otra mecha queda la otra parte satisfecha.

(Sale un mensaxeru)

Mensajero Ñueves bos traygo, Alcalde,

de tristeza y de dolor, que el buesu hermanu Antón Suari queda enterradu en Lleón.

Perdonay isti mensaxe y encomendaréislu a Dios

(Vase)

Alc $A L D E$ Mensaxeru sois, amigu, ñon tenéis lla culpa, ñon. Tornay allá aquesa vara, rabiara yo y ñunca la empuñara, para seme agora tan doloridu. ¡Ay Antton de los mios gueyos tan queridu! Dayme lla capa de bayeta negra que compré pal intierru de mio suegra y el solombreru ñegro sin toquiya que el mio Anton me traxo de Castiya.

EsCRIBANO Mire aquí la capa y solombreru.

$452 \mathrm{~T}$ echay CA me basta hechar 453 CA quenamechando bien lla dicha mecha 454 CA queda lla dicha perra satisfecha. 454 bis CA (Vase Llorente. Sale el mensajero) 455 CA Nueves os trago, el alcalde, 456 CA de tristeza y 457 CA quel vuestro hermano Anton Suare 458 CA queda antarrado en Tamón 459-460 [faltan en CA] 46I CA Mensajero sois, amigo, 463-47I CA tienenla los mios pecados I porquera un anjel Anton 


\section{ALCALDE ¡Ay, hermau y amigo berdaderu!}

EsCRIBANo Dexa, alcalde, plegaries, y fey odenzia.

ALCALDE Emposible yè tener sofrencia, dejame empapellar que yo arrebiento, amigo secretario, con tanto sentimiento. Dexayme empapellar que yo arrebiento porque en echar les llágrimes una a una ñon m’á ganar don Álvaro de Lluna. Y así dexayme llorar amargamente 480 si quier por el dichu de la xente. ¡Ay, cuñada de mio alma y de mio vida, ya ñon saldrás a misa de parida con zapatos y borzeguíes de cueru como Xelemira Gómez y so escuderu!

Pero agora, con tal desasosiegu, ¿quién me ha de echar les berzes en pucheru?, ¿quién me ha de llavar la mi corbata y los mio calzonziyos desfilados, si ñon que me los llaven mio pecados?

EsCRIBANo Si bos parez, Xuan Afonso,

$472 \mathrm{~T}$ berdaru [errata que se corrige] CA Ay, hermano y amigo verdadero! 473 CA Deja y, alcalde, plañer, yde fer audencia. 474-476 [Se sigue la lectua de CA que es más completa] T Emposible ye tener pacienzia / con tantu sentimientu. 477 CA Dejàme 478 CA quen hechar les llágrimes una por una 479 [se sigue la lectura de CA que es mejor] T ñon me a de ganar don Xuan de Lluna. 480 CA y quiero yo llorar 48I CA siquiera por el dicho de la jente 482 CA jAy mio cuñada de llalma y 483 CA à missa de 484-49o [faltan en CA] $488 \mathrm{~T}$ llevar [errata que se corrige de acuerdo al sentido de la frase] 49I CA Dejà yà el llanto por vuestra vida / y, si vòs parez, Juan Fonso 
digamos un responso

por el alma de Anttón que está en folganza.

AlCALDE Dios bos pague la buena rellenbranza.

EsCRIBANO Pos baya con parcemiques reboltiados

y dómenes, donayres gargantiados.

\section{Responso}

Tues Domine Xuan Ramos,

requien alforjele indolojenzia

Cristobalón, Cristobalón papamosques,

perdonando el auditorio

500

el acompañamiento del mortuorio.

492 CA podemos entonar dalgun responso 493 CA pollalma de Antón, questè en folgancia 494 CA Dios vos pague lla bona rellumbranza, 495-496 CA bon modo yisi de consolar altriste / ñon sè esa crianza aù lla aprendiste. I Escribano: Pos si vos queréis quitar lla pena, / cantèmos una lletra que sìa buena. I Alcalde: Decis muy bien, pos aora cantèmos; / cantà vos, que despues yà seguiremos. 496 bis CA (Canta el escribano) 497-50I CA Yá ñon ay mas audencia eñaquistaño / que tray lluto el alcalde por sor mano. 

